\title{
Las secuenciales y estratificadas barreras locales y estatales a la explotación de recursos extractivos*
}

JAN G. LaITOS

Profesor "John A. Carver Jr." en la Facultad de Derecho de la Universidad de Denver.

Elizabeth H. Getches

Abogada de Moye, White, LLP.

SUMARI0:

I. Introducción.

II. Conflictos regulatorios por estratos 0 capas:

1. ¿El derecho de quien prima?

1.1.Disputas entre la Superficie y el Subsuelo;

1.2.Conflictos del GMC: Los pozos petroleros y gaseosos vs. Los pozos de carbón;

1.3. Más conflictos del GMC: El derecho inactivo vs. La fase extractiva.

2. ¿La ley de quién aplica?

2.1. Leyes del Estado vs. Leyes Locales;

2.2. Capas del conflicto asociadas con el desarrollo del GMC:

2.2.1. ¿Es aplicable la ley tradicional de aguas a aquellas producidas por el GMC?

2.2.2. ¿Es aplicable la ley de aguas limpias?

3. Titularidades vs. El poder policía:

3.1. ¿Se aplica la cláusula de expropiaciones?

3.1.1.Cuando el gobierno exige la acción privada;

3.1.2.Cuando el gobierno tiene un nexo suficiente con la acción privada;

3.1.3. El gobierno autoriza a la acción privada, y el daño a otra parte privada es una consecuencia previsible e inevitable.

3.2. ¿Ha habido una expropiación?

III. Barreras Regulatorias Secuenciales Estatales y Locales:

1. Obtener permiso para desarrollar;

2. Durante el desarrollo del recurso;

3. Luego de cesar la producción.

IV. Conclusiones.

Versión originalmente publicada en Virginia Enviromental Law Review, Volume 23, No. 1.

Esta investigación ha sido previamente publicada, en una versión más corta, en "Public Land Special Institute", patrocinado por el Rocky Mountain Mineral Law Foundation (Albuquerque, Nuevo México, Mayo 2003).

La traducción del presente artículo fue realizada por Chiara Lercari Lavezzo y Jorge Liendo Tejada, alumnos del sexto y octavo ciclo respectivamente, de la Facultad de Derecho de la Universidad de Lima. 


\section{INTRODUCCIÓN}

Los proyectistas que explotan los recursos naturales, para su aprovechamiento, a lo largo de America y particularmente en el oeste, buscan la extracción de valiosos recursos energéticos (petróleo, gas, carbón y gas metano de carbón), así como de minerales preciosos (oro y cobre) y de materiales de construcción (piedra, arena y granito). A pesar de que estos proyectistas poseen el derecho legalmente válido para la extracción de los recursos, las barreras regulatorias, tanto estatales como locales, interfieren y en algunos casos prohíben el ejercicio del derecho del proyectista. Por las formas en la que estas barreras se manifiestan pueden ser verticales u horizontales. En la primera, capa tras capa de regulación estatal y local confusa e incierta, obligan al proyectista a gastar tiempo, dinero y esfuerzo en tratar de entender que ley (estatal o local) aplica y como lo haría al desarrollo del proyecto de aprovechamiento de los recursos naturales. En la última, durante el tiempo de vida del proyecto, las restricciones estatales y locales operan algunas veces, con intención impredecible para detener, retardar o poner alto a las actividades extractivas de recursos.

Estos limites gubernamentales son normalmente impuestos en razón a fines ambientalistas, de uso de tierra o jurisdiccionales. Desafortunadamente, no importa cuán digno sea el motivo, la enorme cantidad de estas barreras regulatorias locales y estatales de múltiples y secuenciales capas hacen que el aprovechamiento del recurso demande mucho tiempo y sea muy costoso. La dura resistencia que ofrecen estas regulaciones no-federales, desalienta o inhibe las operaciones, legalmente válidas, de extracción de recurso naturales. Las consecuencias no be- nefician ni a los gobiernos locales que imponen estas barreras, ni a los proyectistas frustrados. Al mismo tiempo el mercado de recursos es una victima, pues ralentiza o detiene el necesario movimiento de commodities, demandados por los consumidores. Sin duda, uno podría sostener que la única parte que se beneficia de esta caótica situación son los abogados de los proyectistas, quienes consagran interminables horas facturables para batallar contra las agencias de regulación locales y estatales.

Especialmente, al oeste intermontano, la explotación del gas metano de carbón (GMC) es particularmente vulnerable a las barreras verticales y horizontales. El GMC es considerado de vital importancia en relación a la creciente demanda nacional de energía'. A pesar de esta necesidad, los proyectistas que buscan explotar el GMC, enfrentan las mismas barreras verticales $y$ adicionales que enfrentan otras industrias extractivas de mineral, así como los propios obstáculos que presenta el desarrollo del GMC². Debido a que, la extracción de GMC tiene un profundo impacto en la cantidad y calidad de agua y en los alrededores, su aprovechamiento frecuentemente afronta específicas regulaciones estatales y locales, pese a que su extracción es relativamente de bajo costo ${ }^{3}$. Las normas ambientales existentes, son poco adecuadas para hacer frente a las consecuencias específicas del desarrollo del GMC. Los abogados de los proyectistas deben litigar para obtener clarificación o encarar una parálisis regulatoria.

En este artículo presentaremos el caso de que la ley, en particular las normas estatales y locales, han devenido en antiéticas en correspondencia con el aprovechamiento racional de los recursos. Primero, consideraremos las muchas capas de

1. BRYNER, Gary C. Coa!bed Methane Development in the Intermountain West: Legal issues and Challenges, TRENDS (ABA Sec. Env't, Energy, \& Res.) Enero/Febrero. 2003, en 8.

2. Id. "Mientras encontramos muchas similitudes en los retos que enfrenta el desarrollo del GMC en el Oeste, cada cuenca es una combinación única de recursos, la cantidad y calidad del agua, el desarrollo de la competencia existente sobre los usos del suelo y sus designaciones, los requerimientos del gobierno y otros factores". Id.

3. Entrevista con Felicity Hannay, representante de la Fiscalía General del estado de Colorado (Marzo 3, 2003). El desarrollo del GMC recibe mayor atención porque el GMC es menos costoso de extraer pues proviene de un estrato más superficial que el gas natural. Al mismo tiempo, la extracción de GMC genera preocupación por su potencial impacto negativo en la calidad y cantidad del agua y otros aspectos del medio ambiente. 
regulación que ocasionan confusión en el proyectista. Esto surge entre (1) Los titulares de los derechos sobre los minerales en la superficie, (2) los productores de carbón y los de gas metano de carbón, y (3) los productores de petróleo y gas y los de GMC, cuando el primero tiene su derecho inactivo y el último se encuentra en el proceso de extracción. Luego, discutiremos sobre la confusión en los proyectistas que causa la incertidumbre de saber que ley aplica y cuál no. La decisión sobre esto ocurre cuando el proyectista (1) confronta regulaciones estatales y locales que compiten entre sí, o (2) cuando encuentra dos regímenes regulatorios sobre el agua totalmente distintos y contradictorios que pueden ser aplicables a la inmensidad de agua producida en la extracción del GMC. Seguiremos con, considerar la desconcertante capa de conflictos legales que enfrentan quienes explotan los recursos: la batalla entre la titularidad privada que se tiene sobre los derechos de propiedad de los recursos, protegida por la cláusula dominante de la Constitución de los Estados Unidos de América, y el poder de policía gubernamental que regula estos derechos de propiedad.

Después de describir las capas de conflicto que funcionan para sofocar la pensada y medida actividad de explotación, trataremos los desalentadores y ralentizadotes patrones de obstáculos regulatorios que son endémicos en los momentos críticos de la etapa de las operaciones extractivas. Describimos los obstáculos de las secuencia barreras de regulaciones locales y estatales, que debe negociar el proyectista durante el desarrollo de las actividades y después del cese de las mismas, al mismo tiempo que lucha por la obtención de los permisos requeridos por las autoridades. Estas barreras varían entre los cambios de zonificación, la mano dura en las condiciones puestas para la obtención de permisos habilitantes, moratoria inesperada, e incluso hasta los rigurosos requerimientos para las reclamaciones correspondientes al cese de las actividades extractivas.

Sugeriremos, a manera de conclusión, que resulta de beneficioso interés para los proyectistas y los reguladores estatales y locales, imponer un set de normas regulatorias racionales y uni- ficadas, para las operaciones extractivas de los recursos. El incremento de predictibilidad ayudará a evitar las demoras, confusiones y litigios que el actual sistema alienta.

\section{CONFLICTOS REGULATORIOS POR ESTRATOS O CAPAS}

Los conflictos regulatorios que los proyectistas enfrentan, mientras operan en tierras no federales, se les conoce como "capas o estratos", que tienden a estar apilados verticalmente entre los distintos regímenes legales. Existen tres clases de conflictos. Los primeros importan determinar el derecho de quién prevalece. Estas disputas surgen de los intereses sobre la superficie y el subsuelo en relación a los distintos minerales. Actualmente, parece que la ley estatal exige que un interés se acomode a otro. Sin embargo, la supuesta acomodación no permite calcular cuánta carga puede imponer el propietario de la superficie a los intereses que existen sobre el subsuelo. Adicionalmente, el proyectista debe estar atento al daño que puede causar al propietario de la superficie, ya que puede encontrarse obligado a internalizar los costos que genere dicho daño. La dificultad se encuentra en anticipar y determinar cuánto daño es suficiente. Esta incertidumbre juega particularmente en contra de los productores de GMC. Muchas disputas involucran determinar quién mantiene la titularidad sobre del GMC. Los estados mantienen distintas posiciones al respecto, por lo que ante la pregunta de si el metano en capas de carbón es parte del carbón o del estado gaseoso, sus reglas resultan contradictorias. Los conflictos en torno al GMC surgen también, cuando el gas metano es explotado cerca de latentes yacimientos minerales de petróleo y gas.

La segunda de clase de conflictos regulatorios resultantes de los estratos verticalmente apilados, intentan determinar la ley de quién aplica. La confusión surge cuando, aparentemente, a los proyectistas se les exige cumplir con inconsistentes leyes locales y estatales. En estos casos, las reglas estatales y locales que establezcan derechos de preferencia deben guiar la resolución del conflicto. El problema de determinar la ley que aplica se torna,

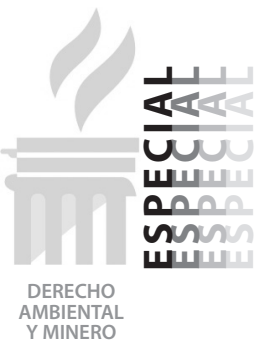


particularmente, profundo con respecto al GMC. Determinar cuál de las distintas leyes que regulan el uso de agua al momento de la extracción del GMC, se ha convertido en un desafío económico y legal constante.

Un tercer estrato nace del poder de policía con respecto a las titularidades en conflicto. Los proyectistas, reguladores gubernamentales, y las cortes frecuentemente deben decidir si la cláusula dominante de la Quinta Enmienda de la Constitución de Estados Unidos aplica como una limitación al poder de policía local y estatal que promulga restricciones a los proyectos de explotación. La aplicación de la Cláusula Dominante se torna particularmente problemática cuando un gobierno local autoriza a un particular a causar daños a un proyectista.

\section{1. ¿El derecho de quien prima?}

El futuro explotador de recursos naturales confronta una esquizofrénica regulación que incluye reguladores estatales y locales armados de tantas reglas y regulaciones como personalidades existen. Como resultado, el productor de minerales debe hacer frente a un marco regulatorio cuyas operaciones y aplicaciones a los proyectos no pueden ser previstas. Esta sección discute tres conflictos no resueltos que los proyectistas afrontan en territorios estatales y locales. Primero, intereses sobre los distintos minerales encaran disputas cuando no existe certidumbre en relación a que interés prevalece, el del propietario de los minerales o el del propietario de la superficie. Segundo, debido a que el GMC es encontrado en vetas de carbón los productores están inseguros si el GMC pertenece al yacimiento de gas o de carbón. Tercero, conflictos estallan cuando los productores de GMC encuentran petróleo y gas en la misma área subterránea en la que se forma el GMC. Debido a que, los pozos de petróleo y gas han sido incorrectamente contenidos o simplemente han sido abandonados y al mismo tiempo al no existir tecnología lo suficientemente confiable que nos pueda indicar la ubicación exacta de los pozos, esta situación representa un daño potencial a quienes trabajan en las minas de GMC.

\subsection{Disputas entre la Superficie y el Subsuelo}

Los conflictos entre los propietarios del suelo y de los minerales son causados cuando pozos minerales se encuentran esparcidos debajo de la superficie 4 . En muchos estados, para el common law, la propiedad sobre los minerales es la propiedad dominante, mientras que la propiedad sobre la superficie es la propiedad sirviente ${ }^{5}$. Esto significa que los propietarios de los minerales son titulares de una servidumbre con respecto a la propiedad de la superficie, cuyo objetivo es usar la cantidad de tierra racionalmente necesaria para poder explotar los minerales ${ }^{6}$.

Este derecho favorece al proyectista, pues esta permitido para su ejercicio ocasionar una determinada cantidad de daño razonable al propietario de la superficie al momento de iniciar las actividades de perforación. Esta ventaja: sin embargo, es limitada. Los propietarios de los minerales no tienen el derecho de destruir, interferir o dañar los derechos correlativos que corresponden al uso u ejercicio de los derechos que posee el propietario de la superficie ${ }^{7}$. Por

4. FISKE, Jeffrey R. \& LANE, Anne E. Urbanization of the Oil Patch: What happens when they pave paradise and put up a Parking Lot, 49 RocKY MTN. Min. L. INsT. 15-1, 15-2 (2003). Como resultado de la separación de la superficie y los minerales, el propietario de la superficie no tiene interés en el mineral ni tampoco sobre las ganancias que puedan derivarse de su explotación, a pesar que la explotación de los minerales constituyen un impedimento para el ejercicio de su derecho sobre la superficie. Id.

5. WITWER, Robert E. Tension Beneath the Surface: The Evolving Relationship Between Surface and Mineral Estates, 30 12 CoLo. Law. 67, 67 (Dic. 2001) (discute las variable legales implicadas en los conflictos superficie - mineral).

6. Notch Mountain Corp. v. Elliot, 898 P.2d 550, 556 (Colo. 1995).

7. Id. 
ello, mientras el uso de la superficie no sea negligente ${ }^{8}$, excesivo o irracional, el proyectista no tendrá la obligación de restaurar al estado original la propiedad de la superficie ${ }^{9}$. Sin embargo, pueden aparecer conflictos porque las normas que regulan el deber de reparar pueden ser contradictorias a las provisiones contenidas en contratos de cesión de propiedad, de arrendamiento y de patentes ${ }^{10}$.

Otra limitación al derecho de uso de la superficie que ostenta el productor de los minerales es la norma que exige tanto al titular de derechos sobre la superficie como el que los posee sobre el subsuelo, a dar la debida consideración a los derechos de cada uno al momento de utilizar la propiedad del titular de la superficie ${ }^{11}$. Esta práctica, adoptada por varios estados, cada uno con sus particularidades, es la llamada la doctrina de la adaptación ${ }^{12}$. Generalmente, el propietario de los minerales debe adoptar formas alternativas de ejercer los derechos que tiene sobre la superficie, pues puede "perjudicar o poner en peligro el derecho del propietario de la superficie" ${ }^{\prime 13}$. Nace confusión en el proyectista al momento de determinar

8. Ver, EnCana Energy Res., Inc. v. Campbell's C-Ment Contracting, Inc., No. 02 CV 643 (Weld County Dist. Ct., Colo., Ag. 7, 2002) (se sostuvo que de una operación de petróleo y gas no resulta necesario encontrar alternativas razonables para la ubicación del pozo para evitar una demanda por negligencia).

9. Amoco Prod. Co. v. Carter Farms Co., 703 P.2d 894, 897 (N.M. 1985). Ver también Exxon Corp. v. Pluff, 94 S.W.3d 22, 30 (Tex. App. 2002) (se resolvió que el arrendatario no tiene la obligación implícita de restaurar la superficie a la terminación del contrato de arrendamiento, en virtud de una disposición en el contrato de arrendamiento que le otorga al arrendatario el derecho de remover la propiedad y accesorios).

10. Tidewater Associated Oil Co. v. Shipp, 278 P.2d 571, 575 (N.M. 1954) (encontrándose responsable a un arrendatario de petróleo y gas frente al dueño de la superficie por daños previstos en el contrato a pesar de que el uso de la superficie no fue negligente, excesiva o irracional), se reafirmó en Dean v. Paladin Exploration Co., 64 P3d 518, 521 (N.M. Ct. App. 2003) (sosteniendo que en donde el acuerdo entre el arrendatario y el dueño de la superficie incluya una cláusula expresa a través de la cual el arrendatario se compromete a pagar por todos los daños causados en la tierra por sus operaciones sísmicas 3-D, el dueño de la superficie no tiene que alegar negligencia o uso excesivo de la superficie cuando se busque daños). Ver, también Corbello v. lowa Prod., 850 So.3d 686, 699-701 (La. 2003) (encontrando que en caso de incumplimiento contractual para "razonablemente restaurar la vivienda lo más pronto posible a su condición actual" indemnizaciones por daños no tiene por qué limitarse al valor de mercado de la propiedad. Los demandantes fueron capaces de lograr la restauración total como indemnización por daños, incluyendo la porción asignada para la limpieza de las aguas subterráneas, aunque los demandantes, como propietarios, no tenían una obligación legal de usar parte de la indemnización para específicamente, limpiar el agua subterránea y a pesar de que las compañías petroleras demandadas tenían un crédito por los montos pagados a los propietarios por una substantive action en la Oficina de Conservación.).

11. Gerrity Oil \& Gas Corp. v. Magness, 946 P.2d 913, 927 (Colo. 1997) citando Grynberg v. City of Northglenn, 739 P.2d 230, 234 (Colo. 1987). Ver, También Burkett v. Amoco Prod. Co., 85 P.3d 576 (Colo Ct. App. 2003) (encontrando que ni el dueño de la superficie ni el arrendantario de un terreno de minerales separado tienen el derecho absoluto de excluirse de la superficie; más bien, cada uno debe tener en cuenta el derecho del otro); Amoco Prod. Co. v. Thunderhead Inv., Inc., 235 F. Supp. 2d 1163, 1171 (D. Colo. 2002) (de acuerdo con Gerrity que estableció que el dueño del mineral debe respetar los derechos del dueño de la superficie, pero el dueño del mineral puede justificar su conducta demostrando que el uso fue razonable y necesario).

12. Fiske \& Lane, supra nota 4, at 15-3. La doctrina de la 'acomodación' involucra un "balance de intereses que compiten entre sí"; especialmente en áreas que están pasando por un proceso de urbanización, los conceptos de "debido respeto" y"acomodación" son difíciles porque se les exige tanto a los propietarios de la superficie como a los de los minerales y la resolución de las disputas se determinan teniendo menos consideración en las doctrinas legales y mas en aspectos técnicos, económicos, junto con los intereses del gobierno local. Id.

13. Gerrity Oil, 946 P.2d en 927. Ver, también ALSPACH, Christopher. Surface Use by Mineral Owner: How much accommodation is required under current oil \& gas law?, 55. Okla. L. Rev. 89 (2002); McFarland v. Taylor, 65 S.W.3d 468 (Ark. Ct. App. 2002) (sosteniendo que donde un dueño de los derechos minerales interponga una demanda contra el dueño de una propiedad para eliminar las obstrucciones de la vía de acceso, y donde una ruta de acceso alternativa a la concesión minera pudo haber sido adecuadamente mejorada y totalmente operativa por no más de US\$ 1,500, por lo que fue apropiado denegar una medida cautelar contra el propietario), citando Martin v. Dale, 21 S.W.2d 428, 429 (Ark. 1929) (encontrando que el uso del dueño del mineral debe ser necesario y lo menos lesivo 
cuándo se generaría "perjuicio" al propietario de la superficie. En algunos estados, la casuística define perjuicio como el uso irrazonable de la superficie por parte de la propiedad dominante ${ }^{14}$. El ejercicio de la propiedad dominante es irrazonable cuando existiendo prácticas alternativa industriales para la extracción de minerales, se causa perjuicio a la propiedad sobre la superficie ${ }^{15}$. Desafortunadamente, esta amplia definición no resulta una herramienta adecuada para la resolución de conflictos.

La forma popular de vivir en el oeste es la de arrojar combustible al fuego. La creciente población en el occidente de Estados Unidos hará inevitable las disputas sobre minerales y suelo ${ }^{16}$. Los estándares legales históricos para la resolución de conflictos se muestran muy a menudo inadecuados, especialmente ante legislaturas estatales que se ven obliga- das a responder a molestos constituyentes temerosos de los intereses del subsuelo ${ }^{17}$. En respuesta, algunos estados han promulgado leyes que norman los daños sobre la superficie, las que "exigen a los propietarios de minerales internalizar los costos de los daños producidos en la superficie"18. Así, el estado de Colorado intenta minimizar conflictos entre los propietarios de la superficie y los de los minerales al dar previo aviso a los compradores de propiedades que no están adquiriendo acceso ni la titularidad de los minerales que se encuentran en la superficie ${ }^{19}$. Estas leyes buscan minimizar los conflictos entre los adquirentes, quienes desconocen la existencia de los minerales que reposan debajo de ellos, y los propietarios de los minerales quienes tendrán que perforar a través de sus tierras. Parece que estas normas representan un giro fundamental hacia la adaptación para los derechos sobre la su-

frente al dueño de la superficie). Pero, ver EnCana Energy Res. No. 02 CV 643 (encontrando que donde un proyectista de petróleo y gas perfore un pozo sin el consentimiento de la compañía minera de la grava, el operador no tiene que perforar direccionalmente en el orden para acomodar la propietario de la superificie).

14. Thunderhead, 235 F. Supp. 2d at 1172 (las normas del estado de Texas sostiene que el uso razonable de la superficie no requerirá que el arrendatario se acomode por el desarrollo de especulaciones residenciales futuras planteadas por el dueño de la superficie). Pero, ver Encana, No. 02 CV 643 (se encontró que un futuro uso planificado del cual el operador de petróleo y gas era consciente que constituye un derecho con el que no debe interferir irrazonablemente). Ver también Burkett, 85 P.3d 576 (una sentencia por la determinación de la cuestión de lo que es razonable y necesario, no podría ser hecha por la petrolera que aún no ha seleccionado los sitios específicos para los pozos propuestos).

15. Ver ld

16. Ver Witwer, supra nota 5, en 67, 69 (discusión sobre las estadísticas que demuestran un incremento significativo de la perforación permitida). Ver, también Fiske \& Lane, supra note 4, en 15-1.

El crecimiento demográfico y la migración de los habitantes de la ciudad a lugares más distantes contribuyó significativamente a las tensiones existentes entre el desarrollo de la superficie y las operaciones de petróleo y gas. Como un ejemplo, en...los... condados de Weld y Adams [en Colorado], el número de permisos de construcción netos se incrementó en un 1500\% durante 1990-2000.

17. Ver también Fiske \& Lane, supra nota 4, at 15-2 (se discute cómo antiguas concesiones de petróleo y gas fallaron al contemplar la "intensidad" de la explotación minera actual a través de la tecnología avanzada y la densidad, el espacio y la ubicación, así como la explotación de minerales en cada vez menores contextos rurales.

18. Ver, Witwer, supra nota 5, en 69, n.38 (citando 765 ILL Comp. Stat. §§ 530/1 et seq. (2003); Kv. Rev. Stat. Ann.§ 353.595 (Michie 2002); Mont. Code Ann.§§ 82-10-501 et seq. (2003); N.D. Cent. Code §§ 38-11.1-01 et seq. (2003)". Okla. Stat. tit. 52,§§ 318.2 et seq. (West 2003); S.D. Codified Laws§§ 45-SA-1 et seq. (Michie 2003); Tenn. Code Ann. $\S \S 60-1-601$ et seq. (2003); y W.VA. CoDE§§ 22-7-1 et seq. (2003)). Ver también Ward Petroleum Corp. v. Stewart. 64 P.3d 1113. 1114 (Okla. 2003) (se señaló que: "el propietario de la superficie puede presentar una reclamación de agravio en el mismo caso en el cual una parte ha iniciado un procedimiento bajo la ley de Daños a la Superficie... [siempre y cuando] el procedimiento legal y la reclamación por agravio se mantengan en dos vías procedimentales distintas, una que se rija bajo la ley misma y otra bajo el código de defensa de Oklahoma).

19. Ver Colo. Rev. Stat. Ann. § 24-65.5-101 (Oeste 2002) (requisito de notificación a los propietarios de varias aplicaciones minerales para el desarrollo de la superficie). 
perficie y más restricciones o barreras para el productor de minerales ${ }^{20}$.

\subsection{Conflictos del GMC: Los Pozos Petrolerosy Gaseosos vs. los Pozos de Carbón}

Presente en cualquier debate que envuelva el GMC existen cuestiones sobre titularidad: ¿quién es el titular del GMC? ¿Lo es quien ostenta derechos sobre el gas o acaso el que tiene derechos sobre el carbón? La naturaleza e historia de su explotación proveen una respuesta intuitiva a estas interrogantes. Determinar la intención de las partes en los dispositivos legales de hace décadas atrás fue particularmente difícil, debido a que el GMC no era considerado como una mayor fuente de energía cuando se adoptaron ${ }^{21}$.

Desde entonces, el GMC ha devenido en un commodity valioso, por lo que los propietarios de los yacimientos de carbón y de gas reclaman al mismo tiempo, derechos sobre el gas metano combinado con el carbón.

Desafortunadamente para el confundido proyectista, las cortes no han resuelto de forma comprehensiva este problema. Las jurisdicciones utilizan distintas reglas e interpretaciones para determinar a quién le corresponde la propiedad del metano proveniente del carbón ${ }^{22}$. La postura federal, adoptada por la mayoría de los estados, sostiene que el propietario de los derechos sobre el petróleo y el gas es titular a su vez del GMC, mientras que el propietario sobre el carbón únicamente tiene derechos sobre este $^{23}$. Esta postura proviene de la sentencia de la Corte Suprema de los Estados Unidos, en el caso Amoco Production Co. v. Southern Ute Indian Tribe $^{24}$. Lo sustentado en este caso se limita a los hechos; sin embargo, la racionalidad que lo caracteriza tiene una potencialidad de aplicación amplia, esto es que el GMC, a pesar de encontrarse en el carbón, no es parte de este ${ }^{25}$. Aún anteriormente a la decisión tomada en Southern v. Ute, el procurador del Departamento del Interior emitió opinión concluyendo que quien ostenta la propiedad sobre el carbón no es propietario del gas en las capas de carbón ${ }^{26}$; concluyó también que el GMC puede ser dado en concesión separadamente, en virtud de la Mineral Land Leasing Act, la misma ley aplicable para las concesiones de petróleo y gas ${ }^{27}$.

Por otro lado, lo estados carecen de regulación de la propiedad sobre el metano dentro de la capas de carbón. Algunas cortes estatales,

20. Pero, ver WONSTOLEN, Ken. Legal, Legislative \& Regulatory Review, Flowline (Colo. Oil \& Gas Ass'n, Denver, Colo.), Nov./Dic. 2002, en 5 (discutiendo una decisión prejudicial planteada por el Juez de la Corte del Distrito del Condado de Weld por lo que "es claro que el permiso del dueño de la superficie no es requerido para entrar a la propiedad para operaciones de petróleo y gas y esa perforación direccionada no es requerida para "acomodar" las preocupaciones del propietario de la superficie".).

21. Amoco Prod. Co. v. S. Ute Indian Tribe, 526 U.S. 865, 876 (1999) (el GMC se 'consideraba un residuo peligroso', en vez de una parte del valioso combustible a base de carbón).

22. Newman v. RAG Wyo. Land Co., 53 P.3d 540, 544-48 (Wyo. 2002) (interpretando la escritura de transferencia "todo el carbón y minerales mezclados con carbón que puedan ser explotados o extraídos en asociación con los mismos o en conjunto con las operaciones de carbón tipo" y las reservas de "todo petróleo, gas y otros minerales" para reservar a los propietarios todo el metano en capas de carbón).

23. LEAR, Phillip W. y SNOW, J. Matthew. Coal and Coalbed Methane Development Conflicts Revisited: The Oil and Gas Perspective. Rocky M'f'I'i. MrN. L. Inst., 10-1, 10-5 (Mayo 2003).

24. S. Ute Indian Tribe, 526 U.S. at 880 (se sostuvo que el GMC era un mineral distinto, separado del carbón de conformidad con la ley de tierras de carbón).

25. Id. en 875 .

26. Lear \& Snow, supra nota 23, en 10-9.

27. Id. (citando Ownership of and Right to Extract Coalbed Gas in Federal Coat Deposits, 88 INTERJOR DEC. 538 (1981)). 
tales como la Corte Suprema de Wyoming y de Montana, coinciden con la postura federal de que el GMC puede ser separado del yacimiento del carbón ${ }^{28}$. La Corte Suprema de Wyoming, en el caso Newman v. RAG Wyoming Land Co. ${ }^{29}$, resolvió que teniendo en cuenta que el GMC es un mineral que no se obtiene en asociación con la extracción del carbón, sino que era obtenido a través de pozos, tal como otros gases ${ }^{30}$, no estaba incluido en el contrato que otorga los derechos sobre el carbón ${ }^{31}$. De forma similar, la Corte Suprema de Montana, explicó que ya que el GMC no era parte "constituyente" del carbón, el gas metano sería separado de los yacimientos de carbón ${ }^{32}$. Como resultado, la transferencia de los derechos de propiedad sobre el carbón no incluyen los derechos sobre el $\mathrm{GMC}^{33}$.

Alternativamente, algunos estados como el de Pensilvania consideran que el GMC es imposible de ser separado del yacimiento de carbón, por lo que no se pueden tener dos derechos de propiedad distintos ${ }^{34}$. En United States Steel Corp. v. Hoge, la Corte Suprema de Pensilvania sostuvo que "el gas [GMC] al encontrarse presente en el carbón, debe necesariamente pertenecer al propietario del carbón, mientras que permanezca bajo su propiedad y este sujeto a su exclusivo domino y control $^{35}$. Sin embargo, el propietario de la tierra mantuvo la titularidad sobre el GMC que escapaba de los bordes de la tierra ${ }^{36}$.

La Corte Suprema de Alabama, creando aún más confusión, a tomado posición por ambas posturas sobre a quien le corresponde ser titular del metano en las capas de carbón. La Corte llegó a la conclusión que (1) el GMC es parte del yacimiento del carbón porque perforar las vetas de carbón donde está el gas metano y minar el carbón, eran dos procesos "imposibles de ser separados" ${ }^{137}$, y que (2) el GMC debería ser tratado como gas natural ${ }^{38}$. Estas posiciones contradictorias solo pueden complicar la situación para el futuro productor de GMC.

\subsection{Más conflictos del GMC: El derecho inactivo vs. La fase extractiva}

Surge más de un problema cuando encontramos capas de metano presentes en las mismas tierras donde hallamos petróleo y gas. Como algunos especialistas sostienen, "la extracción del mineral puede físicamente dañar, contaminar o evitar que se produzca

28. Lear \& Snow, supra nota 23 , en 10-12.

29. Newman v. RAG Wyo. Land Co., 53 P.3d 540 (Wyo. 2002)

30. Id. en 544.

31. Id. en 540; acorde con Harrison-Wyatt, LLC v. Donald Ratcliff, No. 030634 (Va. Marzo 5, 2004). Pero ver, Caballo Coal v. Fidelity Exploration, 84 P.3d 311 (Wyo. 2004) ("[L]os otorgantes reservaron interés mineral no tangible y escogieron transmitir toda la participación indivisa del otorgante sobre el carbón por lo que esté dentro y subyace de las...tierras". La lección es que cuando las escrituras relativos a la propiedad y su transferencia son elaboradas por las cortes, la variable más importante no son necesariamente los precedentes pasados, sino por la creencia de la Corte que las partes intentaron transmitir.).

32. Carbon County v. Union Reserve Coal Co., 898 P.2d 680, 687 (Mont. 1995).

33. Id. en 688

34. Lear \& Snow, supra nota 23 , en 10-10.

35. U.S. Steel Corp. v. Hoge, 468 A.2d 1380, 1383 (Pa. 1983). Ver también Energy Dev. Corp. v. Moss, 591 S.E.2d 135 (W.Va. 2003) (resolviendo, sin sentido en contrario, que un arrendamiento de petróleo y gas no le otorga al arrendatario el derecho de perforar la veta de carbón del arredador).

36. Hoge, 468 A.2d en 1383.

37. Vines v. McKenzie Methane Corp., 619 So.2d 1305, 1308 (Ala. 1993)

38. NCNB Tex. Nat'l Bank v. West, 631 So.2d 212. 228-29 (Ala. 1993) (determinando que la "regla de la captura" que se aplica a otros gases naturales, debe aplicarse al GMC así, porque el metano d ecarbón es casi idéntico a, y migra de la misma manera que, otros gases naturales.). 
la explotación de otro." ${ }^{\prime 39}$. Cuando se trata de minería subterránea "vetas de carbón, petróleo y gas frecuentemente son encontrados en la misma zona geográfica" ${ }^{40}$. Como resultado, cuando se aumenta la presión a los fluidos contenidos en los pozos de gas, los mineros podrían sufrir daño alguno si su equipo hace contacto $^{41}$. Resulta difícil para los trabajadores mineros determinar la ubicación de las pasadas minas, debido a que (1) los requerimientos de reportes no fueron los suficientemente exigidos en el pasado, (2) "no se encuentra evidencia en la superficie sobre la ubicación de pasados pozos" 42 y (3) "la industria minera aún debe desarrollar la tecnología suficiente que permita localizar pozos existentes, desde las minas subterráneas." ${ }^{43}$.

Debido a prácticas tecnológicas anteriores, el reto más grande para los trabajadores mineros de GMC es encontrar exactamente la ubicación de los pozos de petróleo y gas ${ }^{44}$. Esto resulta crucial, ya que si se falla en determinar su ubicación inhabilitará a los trabajadores de adecuadamente posicionar las columnas o los pilares necesarios para proteger el pozo y la mina ${ }^{45}$. Los pozos que han sido impropiamente contenidos o que han sido abandonados constituyen un potencial riesgo para los trabajadores mineros bajo tierra porque contienen fluidos de gas, petróleo y agua ${ }^{46}$.

Las presiones en los depósitos de gas, también presentan un peligro para los trabajadores mineros del carbón cuando operadores de petróleo y gas penetran las vetas de carbón en busca de bolsas de petróleo y gas a baja altitud $^{47}$. Debido a que, se producen grandes cantidades de gas, existe el riesgo de explosión o fuego si es que los pozos se encuentran entre cruzados $^{48}$. Aún en áreas de baja presión en las reservas de petróleo, el peligro ocurre cuando se inyecta gas de alta presión al espacio entre el tubo de revestimiento y de producción para levantar la columna de petróleo ${ }^{49}$. El posicionamiento de pilares de protección alrededor de los pozos de petróleo y gas no es armonioso con la actividad minera del carbón ${ }^{50}$. Los planos de minería deben ser rediseñados para proveer un pilar más largo que lo normal, lo que expondrá al pozo y disminuirá el riesgo de accidentes que puedan sufrir los trabajadores mineros en el subterráneo ${ }^{51}$.

Los depósitos subterráneos de almacenamiento ubicados debajo de las vetas de carbón presentan similares riesgos cuando el gas natural almacenado es inyectado o recuperado ${ }^{52}$. Es-

39. Lear \& Snow, supra nota 23, en 10-16.

40. Id. (citando WASON J. y WHIELDON JR., C. Procedures for evaluating hazards to coal mining operations from hydrocarbon reservoirs 5, 13 (Oficina de Minas, Departamento del Interior de Estados Unidos, Circular de Información $8582,1973)$ ).

41. Lear \& Snow, supra nota 23, en 10- 18.

42. Id.

43. Id. (citando a JOHNSON et. al., How to find abandoned oil and gas wells (Oficina de Minas, Departamento del Interior de Estados Unidos, Circular de Información 8578, 1973)).

44. Lear \& Snow, supra nota 23, en 10- 18.

45. Id.

46. $I d$.

47. Id. en 10-20.

48. $I d$.

49. Id.

50. Id. en 10-21.

51. Id.

52. Id. en 10-23. 
tos dos últimos procesos ocurren a presiones muy altas $^{53}$. Es de vital importancia para del desarrollo del oeste del país, la legislación de la seguridad para practicas mineras y tecnológicas pasadas y las presentes, así como sistemas uniformes de ubicación.

\section{2. ¿La ley de quién aplica?}

Una segunda clase de capas regulatorias aparecen cuando proyectistas, reguladores gubernamentales y cortes, deben decidir cuál de las leyes federales, estatales o locales aplican. El problema más resaltante es la previsión de la actuación estatal y local. Porque los proyectistas enfrentan el poder regulatorio de policía tanto local como estatal, es difícil determinar que ley aplica. Los estados poseen una amplia autoridad para regular el uso de la tierra y la actividad extractiva de recursos, gracias a su poder amplio de policía. Por lo tanto, la regulación de las actividades de petróleo, gas y minería en tierras estatales corresponde a la jurisdicción del estado. Sin embargo, varios estados delegan poder regulatorio en condados, ciudades y pueblos para así controlar bienes inmuebles (los terrenos) y los recursos naturales dentro de sus límites para proteger la salud pública, la seguridad y el bienestar. Como consecuencia, la regulación sobre el uso de la tierra con respecto a industrias extractivas de recursos, teóricamente, está sujeta a ambos controles estatales y locales ${ }^{54}$.

La expansión de la jurisdicción local ha creado nuevas barreras para los productores de recursos, así como nuevos conflictos con las áreas tradicionales de control estatal ${ }^{55}$. Esta confusión puede ser causa de fines legislativos perseguidos por las agencias estatales de petróleo y gas, cuyo mandato es evitar que se produzcan residuos contaminantes, poniéndolas en conflicto con gobiernos locales, que buscan ralentizar la explotación de petróleo y gas. Mayor aún, las regulaciones varían drásticamente de estado a estado y de localidad en localidad ${ }^{56}$. Las disparidades dentro y a lo largo de las jurisdicciones pueden hacer que el cumplimiento de las posibles regulaciones aplicables, sea no solamente un esfuerzo en vano sino un esfuerzo económicamente inviable.

Aún más, las decisiones legales que se tomen con respecto al desarrollo del GMC, tales como las que surgen con respecto a la cantidad y calidad del agua, son también fuente de confusión para los proyectistas. Los trabajadores mineros se encuentran, usualmente, en incertidumbre al no saber que ley aplica para el manejo de la enorme cantidad de agua producida durante el desarrollo de GMC.

Al tratar de resolver este problema de desorden regulatorio, encontramos drásticas diferencias en la regulación del GMC.

\subsection{Leyes Estatales vs. Leyes Locales}

El proyectista de recursos naturales al momento de asegurar la autorización para iniciar y continuar sus actividades de desarrollo a lo largo de toda la fase operativa, encuentra una regulación competitiva a nivel local y estatal. Ellos están acostumbrados al control estatal y local de la actividad de la industria extractiva y los litigios que resultan de las disputas regulatorias ${ }^{57}$. La

53 Id.

54. Ver Bd. of County Comm'rs v. Bowen/Edwards Assocs., 830 P.2d 1045 (Colo. 1992) Las regulaciones locales sobre la extracción de recursos naturales dentro de los condados, ciudades y pueblos, aplican y no son precluidas a menos que exista un 'conflicto operacional' con las regulaciones estatales. Id.

55. WOZNIAK, Michael J. Home Court Advantage? Local Governmental Jurisdiction Over Oil and Gas Operations, 48 Rocky Mtn. Min. L. Inst. 12, 12-3 (2002).

56. BRYNER, supra nota 1 , en 8,9 .

57. KRAMER, Bruce M. Local Land Use Regulation of Extractive Industries: Evolving Judicial and Regulatory Approaches, 14 UCLA J. ENVTL. L. \& Poc'V 41 (199511996). "Encuentra que la población tiende a mostrar un incremento en el desarrollo urbano, mientras que las personas en directo contacto con el desarrollo del proyecto mineral," o que crea conflictos tanto políticos como judiciales. Id. en 41. 
creciente intervención de los gobiernos locales ha creado una sensación total de desorden en los proyectistas. Los gobiernos locales descaradamente reclaman, sin precedente, autoridad sobre la industria extractiva, incluso en tierras federales ${ }^{58}$. La actual ética ambiental y la creciente participación ciudadana son el frente ante esta facultad irrogada de control local ${ }^{59}$. Los gobiernos locales y sus agencias regulatorias buscan representar los intereses de sus constituyentes. En contraste con el estado, las poblaciones locales raramente favorecen las operaciones extractivas de petróleo, gas y minería ${ }^{60}$. Cuando los intereses estatales colisionan con los intereses locales, el proyectista debe invertir tiempo y dinero para descifrar que ley se debe seguir.

Generalmente, los estados poseen un control extensivo, dentro de sus límites, sobre el desa- rrollo del petróleo y el gas ${ }^{61}$. Adicionalmente, los gobiernos locales poseen concurrente autoridad jurisdiccional sobre el uso de la tierra dentro de sus límites ${ }^{62}$. Esto genera la posibilidad de aparentemente suponer la autoridad, donde localidades desean regular y restringir el desarrollo de la actividad extractiva de recursos, lo que esta permitido por ley estatal ${ }^{63}$. Como resultado, ocurre una pugna para la prevención ${ }^{64}$.

Existe tres maneras de que una ley estatal prevenga una ordenanza o regulación de un condado: (1) mediante prohibición legal expresa, (2) infiriendo la intención estatal de ocuparse exclusivamente sobre el (tema); a través de un conflicto operativo, donde la prevención parcial ocurra si los efectos de la ley local entran en conflicto con una ley estatal aplicable ${ }^{65}$. Usualmente, los gobiernos locales no son totalmente bloqueados

58. Moción de los demandantes que combinan una petición de Orden de restricción, Ex Parte temporal y Interdicto Preliminar y Solicitud de Audiencia de Interdicto Preliminar, Bd. of County Comm'rs v. BDS Int'l, No. 98 CV 429 (La Plata County Dist. Ct.. Colo. interpuesta el 21 de enero de 2003), (tratando de exigir al proyectista un contrato federal, en tierras federales, junto con un permiso previamente otorgado por la agencia estatal, para obtener un permiso del condado de Gunnison debido a los impactos potenciales en la salud, seguridad, bienestar e interés publico de los ciudadanos del condado).

59. Ver también Orden de las mociones de juicio sumario por todas las Partes, Colo. Oil \& Gas Ass'n v. Bd. of County Comm'rs, No. 98 CV 429 (La Plata County Dist. Ct., Colo., interpuesta el 2 de marzo de 2001) (apoyando fuertemente la autoridad del condado para regular las operaciones de petroleo y gas, a pesar de derribar la regulación del mismo condado).

60. Entrevista con Ken Wonstolen, Consejero General, Colorado Oil and Gas Association, en Denver, Colo. (Mar. 2, 2003). Oficiales locales son frecuentemente persuadidos por la oposición local al momento de desarrollo el proyecto, a pesar de la gran necesidad de la zona por los recursos de petróleo y gas. Id.

61. WOZNIAK, supra nota 55, en 12-12 ("La autoridad reguladora de los proyectos de petróleo y gas cuenta con amplias facultades legislativas, otorgadas por las leyes de petróleo y gas de cada estado."). En Colorado, La industria de petróleo y gas está sujeta regulación por parte del Colorado Oil and Gas Conservation Commission (COGCC), establecida por la ley de conservación del petróleo y gas. Colo. Rev. STAT. § 34-60-101 et seq. (Oeste 2003).

62. Bd. of County Comm'rs v. Bowen/Edwards Assocs., Inc., 830 P.2d 1045, 1056 (Colo.1992) ("la autoridad delegada expresamente por los condados mediante la ley del Gobierno Local sobre el Control de Uso de la Tierra y el Código de Planificación del Condado, no deja duda que la regulación del uso de la tierra se encuentra dentro del poder legislativo del condado.").

63. Tinicum Township v. Del. Valley Concrete, Inc., 812 A.2d 758, 764 (Pa. Commw. Ct. 2002) (sosteniendo que la ley estatal prevalece sobre la normativa local regulando cuándo, dónde y cómo la voladura podría ocurrir por la extensa regulación sobre minería en superficie va más allá de los tradicionales controles al uso de la tierra). Ver también, Idaho ex rel. Kempthorne v. Blaine County, 79 P.3d 707 (Idaho 2003) (sosteniendo que la ley estatal prevalece sobre la regulación local de zonificación donde la legislación estatal establezca que la dotación de tierras para escuelas públicas que estén sujetas a un arrendamiento minero quedarán exentos del cumplimiento del Local Land Use Planning Act).

64. Generalmente ver, AMENT, Nicole R. A Perplexing Puzzle: The Colorado Oil and Gas Commission Versus Local Government, Colo. LAW., Feb. 27, 1998, at 73 (discute sobre la autoridad del gobierno local que regula bajo a ley del Gobierno Local sobre el Control de Uso de la Tierra y la casuística legal del estado de Colorado).

65. BOWEN/EDWARDS. 830 P.2d en 1056-57. Ver también, Town of Frederick v. N. Am. Res. Co., 60 P.3d 758, 765 (Colo. 
por las agencias de petróleo y gas estatales, a no ser que "la imposición del interés local materialmente impida o destruya el interés estatal." ${ }^{\prime \prime}$.

El estado de Colorado permite un mínimo control local sobre las operaciones de gas y petróleo. Sin embargo, el alcance de tal control permanece poco claro ${ }^{67}$. Una ciudad o un condado pueden adoptar regulaciones sobre el uso de la tierra aplicable a la perforación de petróleo y gas, en el extremo de que dichas regulaciones "sean diseñadas para armonizar las actividades extractivas de petróleo y gas con los planes sobre el uso de la tierra y el interés de desarrollo estatal." ${ }^{\prime 68}$. Ejemplos de dichas regulaciones incluyen el requerimiento a un operador de obtener una licencia para construcción encima de las estructuras de tierra, el mantenimiento de caminos, la entrega de planes de emergencia, y regular la distancia que debe haber entre la construcción y los pozos ${ }^{69}$. A pesar de ello la imposición local de técnicas de perforación de pozos, inclusive donde no existan condiciones similares bajo regulación estatal, puede constituir un "conflicto operacional" haciendo que la regulación local ceda ante los intereses estatales ${ }^{70}$. Cuando el proyectista no puede predecir si debe seguir la ley local o estatal ${ }^{71}$, debe realizar duplicidad de esfuerzo pues se verá en la situación de satisfacer ambas leyes ${ }^{72}$.

Las regulaciones locales pueden resultar ser menos onerosas que los requerimientos estatales ${ }^{73}$.

Las localidades simplemente "Ilenaran" cualquier vacío en la ley estatal. Inclusive, leyes estatales aprobadas federalmente pueden dejar espacio para una adicional regulación local, especialmente cuando la ley federal en cuestio-

Ct. App. 2002) (provee ejemplo en los que las actividades de perforación están sujetas al derecho de intervención preferente de las comisiones estatales de petróleo y gas donde entran en conflicto con leyes estatales, en temas como la reducción del ruido, y las disposiciones de impacto visual).

66. BOWEN/EDWARDS. 830 P.2d en 1059, citando Nat'l Adver. Co. v. Dep't of Highways, 751P.2d 632.636 (Colo. 1988) (observando que el estatuto modificado por la COGCC no se adelante implícitamente a la regulación local de petróleo y gas).

67. Ver Town of Frederick, 60 P.3d en 764 (sin la delineación de qué actividades pueden regular las localidades, la ordenanza municipal no estaba totalmente precedido por la ley del estado); Board of County Comm'rs of La Plata County v. COGCC, 81 P.3d 1119 (Colo. Ct. App. 2003) (la norma de la COGCC es inválida porque le dio a los operadores de petróleo y gas la licencia para hacer omisión a las regulaciones locales, por lo tanto, erosionando el "delicado equilibrio" entre los intereses locales y estatales que rigen las operaciones de petróleo y gas.).

68. Town of Frederick, 60 PJd en 763 (Ciertos asuntos técnicos requieren regulación estatal uniforme, incluyendo la localización de pozos, dimensión de los pozos, la perforación de los pozos, el drenaje de los pozos, prevención de desperdicios, precauciones de seguridad y restauración del medio ambiente. El hecho de que los intereses del estado requieren estos aspectos técnicos sugieren que existen otros aspectos "no-tecnicos que pueden estar sujetos a regulación estatal."). Ver, WONSTOLEN, Kenneth A. Local Control Over Oil \& Gas Development: "How Far Can They Go?", 27th Annual Fall Land Inst of the Denver Ass'n of Petroleum Landmen (Colo. Oil \& Gas Ass'n, Denver, Colo., Nov. 9, 2000), en 4.

69. Town of Frederick, 60 P.3d en 766.

70. Id. en 785, citando Bowen/Edwards, 830 P.2d en 1060.

71. KRAMER. supra nota 57, en 94-95 ("Desafortunadamente no existe un tratamiento uniforme que lidie con el problema de los saltos a los poderes estatales y sub-estatales.") (citando a VALENTE,William P. y MCCARTHY, JR., David. Local Government. Law - Casos y materials 159 (1992)).

72. Ver WONSTOLEN, supra nota 68 , en 1 (proponiendo que desde un punto de vista de eficiencia gubernamental, los gobiernos locales deben aceptar y usar la aplicación de la COGCC para el desarrollo de presentaciones).

73. DK Excavating, Inc. v. Miano, 549 S.E.2d 280 (W.Va. 2001) (para que el propietario de la tierra obtenga el permiso para minería de superficie conforme al SMCRA pues este es previó a la enmienda de West Virginia exceptuando los requerimientos del permiso de actividades mineras menores al desarrollo de la tierra para fines comerciales, residenciales, industriales o usos cívicos). 
namiento, no haga mención al rol del gobierno local dentro del programa estatal ${ }^{74}$.

En ese contexto el intento federal de excluir subdivisiones políticas del estado, no puede deducirse de la autorización expresa dada al estado, porque las subdivisiones son parte de la misma entidad que la ley federal empodera ${ }^{75}$. Desafortunadamente, la oposición local y la necesidad de un permiso de la autoridad local persistirán incluso después de que todas las leyes aplicables parezcan haber sido satisfechas. Los proyectistas enfrentarán constantemente la subsecuente regulación local para poder el importante permiso estatal ${ }^{76}$. En tales situaciones, donde la regulación local aparente exactamente prohibir lo que la ley estatal ha permitido, el prudente proyectista no debería asumir que la regulación estatal prevalece ${ }^{77}$. Frecuentemente, el siguiente paso es el litigio, pero recurrir a las cortes siempre demandará dinero y generalmente ralentizara las operaciones fundamentales.

La raíz de la confusión que resulta de no saber qué ley es la que aplica (la estatal o local) puede que sea los divergentes intereses involucrados. Las metas estatales de proveer energía, a través de la explotación de recursos naturales están inherentemente en contraposición con los gobiernos locales, quienes esencialmente favorecen tener la política de explotación de recursos "fuera de vista". Los estados están interesados en una regulación de lo recursos naturales uniforme y amplia que satisfaga las demandas de sus ciudadanos por fuentes de energía limpias y eficientes ${ }^{78}$. De otro lado, los gobiernos locales están interesados en preservar las comunidades, para que carguen con los costos sociales medioambientales y estéticos de las operaciones extractivas de recursos.

Muchas agencias reguladoras tienen mandatos legales para producir petróleo y gas eficientemente, para proteger los derechos correlativos y para preservar el interés público y privado en la prevención de desechos ${ }^{79}$. Las comisiones estatales de gas y de petróleo son requeridas de balancear deberes regulatorios tradicionales con la protección de la salud pública, seguridad, bienestar y medio ambiente ${ }^{80}$. Sin embargo, para el estado contar con suministros de energía es de "vital importancia para la salud, seguridad y bienestar de las personas"81. Una directriz legal imperativa es la de producir fuentes de energía ${ }^{82}$.

74. Synagro WWT Inc. v. Rush Township, 204 F. Supp. 2d 827, 838 (M.D. Pa. 2002) (resolviendo que la SMCRA no se adelantó a una ordenanza municipal aprobada en virtud de un programa SMCRA aprobado federalmente, ya que la regulación no se refería a las actividades de minería a cielo abierto como se define en la ley estatal).

75. Id. en 837.

76. San Diego Gas \& Elec. Co. v. City of Carlsbad, 75 Cal. Rptr. 2d 534 (Cal. App. 1998) (se llegó a la conclusión que una ordenanza ciudadana que requiere el demandante para obtener un permiso para depositar la arena de sus operaciones de dragado fue precedido por la ley estatal, porque la regulación de las actividades de dragado es "un campo significativo y completamente ocupado por el estado).

77. Independence Excavating, Inc., v. City of Twinsburg, No. 20942, 2002 WL. 2009464, en *2 (Ohio Ct. App. Sept. 4, 2012) (sosteniendo la zonificación no conforme de un municipio para la minería de cielo abierto no fue precedido por una ley estatal que establece las licencias y regulaciones, cuando la local adoptó la prohibición, además por la seguridad y salud pública).

78. WOZNIAK, supra nota 55 , en 12-20 a 12-21.

79. Id. en 12-12, 12-21 (Los estados se preocupan también por proveer energía confiable a precio bajo, manteniendo los puestos de trabajo, y protegiendo el ambiente).

80. Id. en 12-13 ("Muchos estados occidentales han expandido su jurisdicción... para incluir asuntos específicos de salubridad, seguridad, bienestar y mediombiental." En Colorado, la COGCC "es el encargado de promulgar regulaciones y normas para proteger la salud, seguridad, y el bienestar del público en general en los proceso de explotación de la industria de petróleo y gas." \} (citando a CoLo. REv. STAT. ANN. § 34-60-106(2)(D) (1998 \& Supp. 2002)).

81. Colo. Rev. Stat. Ann. § 29-20-108(1) (a) (2002).

82. Ver Meriin Myers Revocable Trust v. Yellowstone County, 53 P.3d 1269, 1270-72 (Mont. 2002) (La Corte Suprema 
Salud pública, seguridad y bienestar, significan algo distinto para las localidades. Para los gobiernos locales hacer frente a las propuestas de desarrollo compensando los intereses locales incluye la preservación en general, "ruido, estética, impacto visuales, paisajes, la protección de hábitats, impacto en la vida silvestre, humedales, áreas naturales, planes de emergencia y requisitos de fianzas." ${ }^{83}$. En consecuencia, al considerarse las propuestas de desarrollo de recursos naturales dentro de la su jurisdicción, los gobiernos locales se concentraran en el impacto de dicho desarrollo. Los constituyentes presionarán a las autoridades locales escogidas para frenar el desarrollo de los recursos ${ }^{84}$. La principal corriente de valores medioambientales y el fenómeno de "no en mi jardín trasero" han proveído incentivos para que las localidades prohíban el desarrollo de actividades de la industria extractivas ${ }^{85}$. Usualmente, no se encuentra apoyo electoral local para la aprobación de grandes proyectos de explotación de recursos ${ }^{86}$.
Los estados han adoptado regulaciones en un intento de lidiar con las preocupaciones gubernamentales. El estado de Colorado, probablemente tenga el nivel de intervención más extensivo en el proceso de otorgamiento de licencias ${ }^{87}$. La Comisión de Colorado de Conservación del Petróleo y el Gas (COGCC, por sus siglas en inglés) han adoptado reglas y procedimientos para acomodar a lo gobiernos locales e incorporar, en la toma de decisiones, la preocupación e inquietudes de los ciudadanos locales ${ }^{88}$. Por ejemplo, una de las reglas impuestas por la COGCC que se les notifique a los gobiernos locales "por adelantado las aplicaciones para obtener el permiso de perforar y una invitación a participar in situ en las consultas con los propietarios de la superficie, con respecto a la ubicación del pozo, el tipo y el lugar donde estarán los caminos y las instalaciones de producción, así como el tiempo de las operaciones ${ }^{89}$. Más importante aún, "se les da a los gobierno locales el derecho de intervenir en, virtualmente, cada procedimiento de la COGCC

de Montana confirmó la decisión de la corte del Distrito de revocar la decisión de los comisiones del Condado que denegaban un permiso de explotación minera de grava en el suelo basándose en que "permitir la aplicación violaría los derechos constitucionales de los estudiantes de Montana a un [vecindario de su escuela] limpio, saludable, sano ambientalmente." La corte suprema del estado afirmó que la dependencia de la corte del Distrito en las leyes de zonificación de Montana que prohibía ordenanzas, resoluciones o medidas que hubieran permitido desarrollar el recurso. Al igual que la corte del distrito, la corte suprema del estado también erró al analizar la constitucionalidad de la ley de zonificación estatal bajo las previsiones ambientales constitucionales de Montana.). Pero ver, Mont. Envtl. Info. Ctr. V. Dep't of Envtl. Quality, 988 P.2d 1236 (Mont. 1999) (sosteniendo que uno de los derechos fundamentales garantizados por la Constitución de Montana es a un limpio y saludable medio ambiente, y que cualquier medida o ley que implique este derecho sería sometido a un estricto escrutinio); Cape-France Enter. V. Estate of Peed, 29 P.3d 1011, 1017 (Mont. 2001) (encontrando un contrato ilegal en donde su desenvolvimiento podría resultar una significativa o substancial degradación ambiental).

83. WOZNIAK. supra nota 55, en 1222.

84. Id. "Es muy probable que los cometidos locales que sean determinados por presiones públicas y políticas, tales como el síndrome de "not in my backyard". Id.

85. NOLON, John R. Discovering Local Enviromental Law, 25 Zoning \& Plan L. Rep. No. 10, en 73, 77 (Nov. 2002) (concluyendo que evolución "gradual hacia la sensibilidad ambiental en los controles del uso de la tierra ha procedido bastante más que otra distinta ética ambiental, en oposición hacia una incidental, es evidente").

86. WONSTOLEN, supra nota 68 , en 7 . Con "un distrito electoral que impide el desarrollo de recursos mayores... los políticos locales se adhieren al lado opositor, al menos si desean ser reelegidos". Id.

87. WOZNIAK. supra Nota 55, en 12.15 .

88. Ver, WONSTOLEN, supra nota 68, en 5, n. 11-12 (citando las reglas 303.d y 306.a (3) de la COGCC)

(“Los gobiernos locales podrán requerir una demora de diez días en la cuestión de un permiso para perforar con el fin de considerar los impactos locales...").

89. Id. 
con el fin de llamar la atención sobre temas de salud pública, seguridad y bienestar." ${ }^{\prime 90}$. Estos procedimientos proveen una participación local sin paralelos. Desde el punto de vista de un proyectista, dicha participación inicialmente llama a la duda sobre si el desarrollo de la actividad extractiva resulta muy costoso y, si no, debe tomarse en cuenta la litigación ${ }^{91}$.

\subsection{Capas de Conflicto asociadas con el desarrollo del GMC}

La explotación de GMC se expande en el oeste, especialmente en Nuevo México, Utah, Colorado, Wyoming y Montana. Para los productores de energía el GMC es un recurso con altísimo potencial económico relativamente no explotado. Puede resultar una manera de satisfacer la aparente insaciable demanda de combustibles de combustión limpia por parte de las centrales eléctricas y del sector doméstico ${ }^{92}$. Pese a ello, los beneficios del aprovechamiento del GMC entran en conflicto con su costo ambiental ${ }^{93}$.

Debido a su naturaleza, el GMC produce vastas consecuencias ambientales ${ }^{94}$. No obstante las operaciones que se llevan acabo para su aprovechamiento son bastante extensas porque son menos costosas y concentradas, ya que los pozos pueden estar cercanamente más espaciados $^{95}$. El esfuerzo para la explotación de GMC en comunidades locales es exacerbado por la rápida velocidad con la que ocurre el proceso de explotación, expandiéndose a través del campo aparentemente sin límites ${ }^{96}$. Naturalmente, mientras mayor contacto tenga las personas

90. Id. en 5, n.15 (citando la Regla 509.a de la COGCC) (se declaró que la intervención del condado en respecto a las áreas de perforación y de sus intensidad se resolverá en dos audiencias, la primera una audiencia técnica, seguida por una audiencia de 'asuntos públicos').

91. WONSTOLEN. Nota supra 68, en 6. Los procedimientos con participación local resultan "un retraso para la perforación de nuevos pozos...Condiciones de aprobación, incluidos planes de desarrollo, inspecciones in situ, los "APD's" tendrán que ir a la audiencia y requerimientos de perforaciones direccionadas podrán ser impuestas al operador" para estar conforme con las reglas. Id.

92. BRYNER. Supra nota 1, en 8.

93. Generalmente, ver DARIN, Thomas F. y BEATIE, Amy W. Debunking the natural gas "clean energy" myth: Coalbed methane in Wyoming's Powder River Basin, 31 Envtl. L. Rep. 10,566 (2001).

94. Ver, MILLER, Zach C. y GEER, Susan J. New Tune for the Miner's Canary: Permitting and Environmental Issues in Coalbed Methane Development, 46 Rocky Mtn. Min. L. Inst. 9-1, 94 a 9-8 (2000). Ver También, THRONE, Mary A. Air Quality Issues in Coalbed Methane Development, en 4 Rocky Mtn. Mjn. L. Found., REGULATION AND DEVELOPMENT OF COALBED METHANE 14-1 (Nov. 2002). Históricamente, el GMC era considerado un nocivo contaminante del aire y un grave peligro para la seguridad de los mineros subterráneos del carbón. El moderno aprovechamiento del GMC, convertido el gas metano en un commodity rentable. Sin embargo, los problemas entorno al cumplimiento de la calidad del aire pueden aún persistir. Se requieren permisos para los motores tales como motores de compresores y generadores diesel portátiles necesarios para producir y transportar el metano antes de que la producción ocurra. Bajo la Ley de Aire Limpio (LAL), los estados y gobierno locales tienen la responsabilidad primordial de aplicar los requisitos federales aplicables a las fuentes fijas de contaminación del aire. Los métodos estatales de regulación incluyen planes de implementación, revisión de la construcción previa, y áreas de incumplimiento. Una instalación de GMC una fuente mayor, dentro de los términos de la LAL. Más probable es que, sin embargo, un motor de producción de GMC constituya una "menor" fuente. Desafortunadamente, las regulaciones que aplican las fuentes menores varían de estado en estado, lo que implica que los explotadores de GMC que operan en distintos estados, debería contar con un multitudinario estándar de regulación. Adicionalmente, las emisiones de GMC pueden estar sujetas a regulaciones regionales poco claras. No es claro si un operador requiere obtener un permiso de contaminación del aire para una planta en particular, ya que puede depender de varios factores tales como la ubicación, las condiciones actuales del aire, y el tamaño de las instalaciones. THRONE en 14-1 a 14-27.

95. Ver Hannay, supra nota 3.

96. BRYNER, Gary C. Coalbed Methane Development in the Intermountain West:Primer, in Rocky Mts. Min. L. Fund., Regulation and Development of Coalbed Methane 13-1 (Nov. 2002) La perforación y construcción es más rápida para los GMC a diferencia del gas convencional. Los GMC pozos tomarán un par de días perforar y otros dos días más para completar, teniendo en cuenta que los pozos convencionales podrían tomar entre 45 y 60 días perforar y completar. Id. 
con tal expansión no controlada, mayor resistencia encontraran los proyectistas por parte de los ciudadanos. Los productores de GMC están encontrando mayor oposición de los gobiernos locales de la que enfrentaron aquellos productores tradicionales de petróleo y gas ${ }^{97}$.

La fácil de observar explotación del GMC ha provocado continuas protestas con los proyectos en desarrollo ${ }^{98}$. En un imprudente desafío a la autoridad estatal, un condado desafió a la agencia estatal de petróleo y gas denegando el otorgamiento de permisos locales para realizar actividades de perforación a una compañía de petróleo y gas que ya había obtenido el permiso para perforar por parte de la comisión de petróleo y gas ${ }^{99}$. En otros condados, se usan suspensiones para estudiar los efectos de la explotación de GMC en la tierra ${ }^{100}$.

La gran mayoría de la oposición a la industria del GMC comprende problemas de agua. Cuando se extrae GMC se generan impactos en el abas- tecimiento y calidad de agua. En el árido oeste, cualquier extracción de recurso que afecte la calidad del agua, los derechos sobre el agua o concerniente al suministro de agua en general, causa controversia. La co-producción de agua durante la extracción de GMC ocurre, debido a que las vetas de carbón deben ser drenadas o despresurizadas bombeando afuera el agua de los pozos antes de que el gas afluya ${ }^{101}$. La cantidad de agua producida puede ser sustancial ${ }^{102}$. Se ha prestado mayor atención al agua obtenida de la extracción de GMC que aquella resultante de la tradicional operación para la extracción de petróleo y gas, debido a que en el primer caso el agua obtenida es de mayor calidad y cantidad ${ }^{103}$. Como consecuencia, se sostiene que el agua producida por el GMC no debe ser tratada de la misma manera de aquella que resulta de distintas operaciones extractivas, consideradas aguas residuales. En cambio, el argumento es que el agua obtenida del GMC, sea tratada como nueva agua, sujeta a tratamiento ${ }^{104}$. Determinar cuando esta agua puede considerarse como residual

97. RING, Ray. Backlash: Local Governments Tackle an in-your-face rush on Coalbed methane, High Country News, Vol. 34, No.2, Sept. 2 2002, en 9. Inicialmente, el impacto del desarrollo del GMC incluía la construcción de caminos, plataformas de perforación, sitios de disposición de agua y facilidades afines. Luego, los residentes vieron los impactos de la operación de estas facilidades, como el ruido de las bombas, el tráfico y las compresoras, emisiones particulares de las compresoras y tráfico vehicular. Id.

98. HARDEN, Blain y JEHL, Douglas. Ranchers Bristle as gas wells loom on the range, N.Y. Times (Late ed.), Dic. 29, 2002, § 1 , en 1 .

99. WONSTOLEN. Supra nota 68, en 5 (La Junta de Comisionados del Condado de County, Colorado le denegó a Gunnison Energy Corporation el permiso para pruebas en cuatro pozos y adjunto treinta y tres condiciones en un quinto pozo después que Gunnison Energy recibió el permiso para perforar por parte de la agencia estatal, la COGCC.).

100. N. Plains Res. Council v. Mont. Bd. of Oil \& Gas Conservation, No. C-DV-2000-177 (Mont. Dist. Ct., interpuesta el 10 de marzo de 2000) (exige que, cuando se impuso una moratoria a la espera de una Declaración de Impacto Ambiental (DIA), la DIA debió ser llenada por la Oficina de Manejo de Suelos, agentes reguladores estatales, la Junta para la Conservación del Petróleo y Gas de Montana y el Departamento de Calidad ambiental de Montana).

101. BRYNER. Supra nota 96, en 13 ("[P]ara desarrollar el recurso, primero las compañías deben bombear grandes cantidades de agua de la tierra, aproximadamente 12,000 galones en promedio por día para liberar el pozo de metano.").

102. Id. (citando Draft Enviromental Impact Statement and Draft Planning amendment for the Powder River Basin oil and gas project (Departamento de Interior de los Estados Unidos, Oficina de Manejo de Suelos, Vol. 1), en 21-24 (En la porción de Wyoming del proyecto Powder River Basin se estima que en los próximos quince años alrededor de 1.4 trillones de galones de agua será producida.)).

103. Id. en 33. El agua producida por los GMC no se acerca a la pobre calidad de agua producida por el petróleo y gas, el cual puede alcanzar un nivel total de sólidos disueltos de cinco a diez veces siendo un agua producida por el peor metano de carbón y, en algunos casos, es de relativamente gran calidad. Id.

104 DARIN, Thomas F. Waste or Wasted? Rethinking the regulation of Coalbed Methane Byproduct water in the Rocky Mountains: A comparative analysis of approaches to CBM produced water quantity legal issues in Utah, New Mexico, Colorado, Montanda and Wyoming, Coalbed Methane Development in the Intermountain west, en 187. 
o como tratable, es otra capa de confusión con la que el proyectista debe lidiar y litigar y luego ser resuelta por agencias gubernamentales $y$ por las cortes ${ }^{105}$.

Frecuentemente, el agua producida por la extracción de GMC es gestionada mediante dos maneras: la inyección en el subsuelo y la eliminación de la superficie ${ }^{106}$. Esta última es, particularmente, controversial porque fuerza el cuestionamiento sobre si el agua es contaminante y, por lo tanto, residual o si es nueva agua, sujeta posiblemente tratamiento ${ }^{107}$. Para decidir sobre el asunto debe determinarse quién es titular sobre la nueva agua y como el resultante efecto ambiental deberá ser regulado.

\subsection{1.¿Es aplicable la ley tradicional de aguas a aquellas producidas por el GMC?}

Generalmente, la ley estatal controla la problemática sobre los derechos del agua. En su mayoría, los estados del oeste aplican la doctrina del tratamiento de las aguas subterráneas. $\mathrm{Si}$ el agua es bombeada desde la tierra, luego desviada y puesta para su benéfico óptimo, un derecho estatal sobre el agua es creado. Varios estados sin embargo, regulan la retira- da del agua de la producción de GMC de la misma manera como lo hacen con respecto a la extracción de petróleo y gas. El estado de Montana es el único que trata el GMC, directamente en sus leyes ${ }^{108}$. En Colorado, Utah, Nuevo México y Montana, el agua removida de un yacimiento de GMC es considerada como "residuo de exploración y producción", sujeta al control y jurisdicción de la comisión estatal de conservación del petróleo y gas ${ }^{109}$. Esto quiere decir que el productor no requiere probar el aprovechamiento beneficioso del uso del agua para poder obtener su permiso para retirarla. El único estado que considera que el bombeo de agua subterránea, solamente para la actividad de perforación en el GMC, constituye un uso beneficioso de las aguas, es el de Wyoming. Por lo tanto ahí, los proyectistas deberán obtener un permiso de tratamiento de aguas subterráneas antes de que sean desviadas a la superficie como el resultado de la extracción de GMC ${ }^{110}$.

Dada la confusión, sobre qué régimen legal tiene jurisdicción sobre el agua producto del GMC, no es sorpresivo que cuando las nuevas aguas son subsecuentemente puesta a uso beneficioso, como en los casos de almacenamiento de agua, varias agencias estatales reclamen

105. HANNAY, supra nota 3. Porque toda cuestión con los GMC no está resuelta, la actual legislación, las reglas y los litigios, están sujetas a cambios.

106. MILLER. supra nota 94 , en $\S 9.02$ ("Las disposiciones de la superficie, por lejos, han generado la mayor controversia y presentan las mayores dificultades regulatorias obstaculizando como ninguna otra la cuestión ambiental asociada al desarrollo del GMC.").

107. Id.

108. Mont. Code. Ann. § 82-11-175 (2000). Ver también, FOGNANI, John D. y HEGARTY, Michael T. Regulation of Produced Water from Coalbed Methane Development in the Rocky Mountain West. Rocky Mont. Min. L. Fund., Special Inst.: Regulation and Development of Coalbed Methane, Volume 2002, No. 4 (Nov. 14.15,2002) en la Investigación 12-B (discutiendo la cobertura regulatoria estatal por el Departamento de Recursos Naturales y Conservación de Montana sobre el agua producida (manejo del agua y acuerdo de mitigación), Junta para la Conservación del Petróleo y Gas, Departamento de Calidad Ambiental).

109. Ver, e.g., Colo. Rev. Stat. § 34-60-103 (4.5) (2001); Ver también, la Regla 907 de la COGCC (se otorga un número de opciones de desecho para el agua producida incluyendo la reinyección, la evaporación, la filtración, drenaje superficial, la difusión y el camino de propagación). Desperdicios de exploración y producción' significa la cantidad de agua que resultante de las actividades de perforación y de producción de los pozos de petróleo y gas o durante las operaciones de campo primarias que están exentas de regulaciones como residuos peligrosos bajo disposición del subtitulo C de la ley federal de Conservación y Recuperación de Recursos del año 1976. Id.

110. Wyo. Stat. §§ 41-3-903 a -905 (2000). En Wyoming, el permiso para el desvío de aguas solo es concedido cuando el desvío tiene fines beneficiosos. El Ingeniero del estado considera como uso beneficioso traer las aguas subterráneas a la superficie en relación al desarrollo del GMC. FOGNANI, nota supra 108, en 12B-9. 
derechos sobre el agua ${ }^{111}$. Los explotadores de GMC se encuentran en el centro de la lucha entre las agencias de petróleo y gas, los ingenieros del estado, y las cortes estatales que buscan el control jurisdiccional sobre el agua que ha emergido del esfuerzo del proyectista.

Los que explotan el GMC, a pesar de no requerir permisos para el agua, encontrarán resistencia de los vecinos y de aquellos afectados por el aumento extra del agua. Los remedios legales estatales protegen los derechos de agua de los que han sido afectados por el desarrollo del GMC, admitiendo demandas civiles por daños y perjuicios. Los propietarios del suelo han alegado traspaso de la propiedad y daños por las descargas de agua producidas por el GMC ${ }^{112}$.

\subsection{2. ¿Es aplicable la Ley de Aguas Limpias?}

Aún no siendo un requisito los permisos de agua, la eliminación del agua producida por el GMC en la superficie se encuentra sujeta a las leyes y regulaciones de la calidad de agua. La
Ley de Aguas Limpias ( $L A L)$ puede entrar en aplicación cuando el agua obtenida del GMC es descargada en un arroyo, drenaje o en un estanque ${ }^{113}$. Si, la LAL es de aplicación el proyectista deberá obtener un permiso del Sistema Nacional de Eliminación de Contaminantes (SNEC) ${ }^{114}$. Los estándares para la obtención del permiso dependerán en distinto factores; haciendo que cada permiso sea único e impredecible para el productor de GMC. Por ejemplo, saber si un permiso del SNEC es una opción o no, puede depender de las aguas receptoras porque los vertidos en ciertas aguas necesitan reservar las limitaciones de efluentes, que son al mismo tiempo tan estrictas que eficientemente prohíben residuo alguno ${ }^{115}$.

Adicionalmente, los estados no están permitidos de hacer excepciones con respecto a la (LAL) cuando se trate del agua producida por gas metano de carbón ${ }^{116}$.

Las cargas regulatorias se tornan aún más complejas cuando, estados como Wyoming exigen

111. Memorándum de Hal Simpson, Ingeniero Estatal, Colorado, al ínterin legislativo del Comité de Petróleo y Gas, (29, Sept. 1999) (discutiendo la superposición de cuestiones jurisdiccionales entre la Comisión Conservadora de Petróleo y Gas, la División de Recursos Hídricos y la Comisión de Control de Calidad de Agua del Departamento de Salud Pública y Medioambiente. "Cada uno tiene autoridad ya que se relacionan al retiro, uso y/o desecho de el agau producida por un pozo de GMC, y la extrema complejidad de la interrelación entre la disposición constitucional, el lenguaje legal, y las diversas reglas existentes."). Ver también, Tongue River Water Users Ass'n v. Mont. Dep't of Envtl. Quality, No. BDV-2001-258 (Mont. Dist. Ct. Interpuesta el 23 de abril de 2001, modificada el 17 de mayo de 2001) (señalando que el desperdicio de agua puede ser ordenado por el ingeniero de estado o por una medida cautelar).

112. Ver, HAND, M. Krisreen y SMITH, Kyle R., The Deluge: Potential Solutions to Emerging Conflicts Regarding On Lease and Off-Lease Surface Damage Caused by Coal Bed Methane Production, 1 Wvo. L. Rev. 661, 682-688 (2001).

113. FRANZ, Holly J. y WATSON, Rebecca W. Coalbed Natural Gas and Water Management:Water Appropriation, Water Quality, and Water Conflicts, 47 Rocky Mnt. Min. L. Inst. En17-17 (2001); ver también, WILLIAMSON, Carrie L. "But You Said We Could Do It!" Oil Companies Liability for the Unintended Consequence of MTBE Water Contamination, 29 ECoLOGY L. Q. 315 (2002).

114. 33 U.S.C.A. $\$ 1362(12)(A)$ (Un permiso de la National Pollutant Discharge Elimination System es exigido para la adición de cualquier cuerpo contaminante en aguas navegables desde cualquier fuente de emisión."). “El agua obtenida del GMC es 'contaminante' es un 'desperdicio industrial' y 'agua producida', tal como lo define la ley de Agua Limpia. Ver N. Plains Res. Council v. Fidelity Exploration \& Dev. Co., 325 F.3d 1155, 1160-61 (9th Cir.2003), cert. denied, 124 S. Ct. 434 (Oct. 20, 2003).

115. Ver N. Plains, 325 F.3d at 1162 (contaminación o alteración hecha por el hombre sobre el medio ambiente bajo los supuestos de la ley de Agua Limpia, es propia de aguas producidas por el GMC y que eran vertidas en los ríos y alteraba la calidad del cuerpo receptor).

116. Id. en 1164. "El estado de Montana no tiene autoridad para crear un permiso que permita la exención de la Ley de Agua Limpia para los vertidos, que de lo contrario estaría sujeto a los procesos de obtención de permisos de la National Pollutant Discharge Elimination System." Id. 
a los productores de GMC obtener no solo un permiso del ingeniero estatal, sino también un permiso del SNEC para verter agua en la superficie y en estanques de contención. En este estado, el proyectista necesita dos permisos: uno del estado para poder tratar las aguas y luego desviarlas y otro del SNEC para el vertimiento. Mientras que estos permisos son otorgados para el vertimiento fuera del cauce de los estanques de contención, las organizaciones medioambientales están actualmente impugnando este proceso por el Powder River Basin ${ }^{117}$.

El agua procesada por el desarrollo del GMC, aunque se considere relativamente "limpia" en comparación con otros tipos de agua procesada, puede ser alta en salinidad o en sólidos totales disueltos (STD ${ }^{118}$. Una vez que la Ley de Agua Limpia (LAL) se activa, muchos de los requisitos federales pueden aplicar a un operador. Además del permiso del SNEDC (Sistema Nacional de Eliminación de Descargas Contaminantes), estos requerimientos incluyen requisitos de anti-degradación aplicables, las normas del estado para el uso del agua de conformidad con la LAL (§401), y los requisitos de la Carga Total Máxima Diaria $(\mathrm{CTMD})^{119}$. Adicionalmente, si hay descarga sobre los humedales el Army Corps of Engineers puede requerir de un permiso $404^{120}$. Finalmente, si es agua se elimina mediante inyección subterránea, el Control Subterráneo de Inyección puede solicitar un permiso ${ }^{121}$. La LAL generalmente aplica únicamente a las aguas superficiales, por lo que la mayoría de los estados del oeste regulan los vertidos de aguas (GMC) residuales a las aguas subterráneas como un asunto de una ley estatal de calidad del agua ${ }^{122}$.

\section{Titularidades vs. El poder policía}

Una capa final de conflictos regulatorios surge cuando los proyectistas afirman controles constitucionales protectores de la propiedad en la potestad reglamentaria estatal y local. Los proyectistas que buscan explotar sus derechos sobre el sub suelo se encuentran a menudo atrapados en luchas con los funcionarios locales y estatales cuyas regulaciones amenazan con limitar el uso de su propiedad. Cuando los derechos constitucionales de la Cláusula de Expropiación de la Quinta Enmienda están en discusión, proyectistas, gobiernos, y últimamente tribunales están confundidos acerca de si las garantías constitucionales prevalecen sobre el poder del gobierno para regular la propiedad.

En el intento de resolver este conflicto, las partes deben responder dos preguntas. En primer lugar, las partes involucradas deben determinar si la Cláusula de Expropiaciones se aplica en todo, especialmente si el proyectista del recurso ha sido limitado por acción privada autorizada por la ley local. En segundo lugar, si se aplica, los proyectistas deben determinar si ha habido una expropiación siguiendo el sentido de la Quinta Enmienda.

\section{1. ¿Se aplica la cláusula de expropiaciones?}

Cuando el gobierno trata de restringir directamente titularidades, la Cláusula de Expropiacio-

117. Wyo. Outdoor Council v. Wyo Dep't. of Envtl. Quality, No. 02-3802 (Wyo. Envtl. Quality Council, filed June 19, 2002). Los demandantes solicitaron al Consejo de Calidad Ambiental de Wyoming la revisión de un permiso emitido por el Departamento de Calidad Ambiental de Wyoming basándose en que no estaba autorizado por las regulaciones de calidad del agua de Wyoming, no se permitieron comentarios del público, y autorizó la construcción de unidades de contención sin permiso y sin normar suficientes que regulen su construcción.

118. FRANZ, supra nota 113 , en 17-25.

119. LAITOS, Jan G. Natural Resources Law, 2002, en 85. (Un CTMD representa "la cantidad más grande de contaminantes que el agua puede recibir sin violar los estándares estatales de calidad del agua").

120. Ver FRANZ. supra nota 113, en 17-25.

121. Para una discusión sobre requerimientos para inyecciones en el subsuelo, ver MILLER, supra nota 94, en 9-17 a la 9-22.

122. Ver FRANZ, supra nota 113, en n.209, (citando Mont. Code Ant. §75-5-103(29) (2000); Wyo. Stat. Ann. §35-11-103(c) (vi) (2000); and Colo Rev. Stat. §25-8-103(19)(2001). 
nes puede limitar dicha acción ${ }^{123}$. Sin embargo, la aplicabilidad de la Cláusula de Expropiaciones se vuelve problemática cuando el gobierno mismo no restringe las titularidades sino más bien autoriza una acción privada que afecta el derecho. Surge la pregunta cuando gobiernos locales aprueban permisos de desarrollo de superficies situadas en lo alto de fincas minerales cortadas. Evidentemente, el desarrollo de dicha superficie hace que el derecho del dueño del mineral a acceder a su finca mineral sea una tarea difícil, por no decir imposible. Si el gobierno estuviera desarrollando la superficie y, por tanto, interfiriendo con el derecho del dueño del mineral a desarrollarla, la interferencia del gobierno sin duda constituiría una expropiación. Si una expropiación ha ocurrido es menos claro, sin embargo, en una parte privada el desarrollo de la superficie está actuando de conformidad con la autorización o aprobación del gobierno.

Esta confusión nace del hecho de que la Cláusula de Expropiaciones solo se aplica cuando el gobierno interviene como actor ${ }^{124}$. Si el actor gubernamental no es responsable de la acción privada, el dueño del mineral perjudicado no puede reclamar al gobierno; la acción debe ser en agravio del actor privado ${ }^{125}$. Para que el gobierno local sea responsable en la expropiación, el gobierno debe ser encontrado responsable por las acciones de la parte privada que causaron la expropiación de los intereses de propiedad del dueño del mineral.
Hay tres clases de casos que indican si las acciones privadas tomadas en virtud de la autorización del estado se convierten en acción del gobierno. En las siguientes situaciones, acciones privadas que afecten el interés sobre minerales podrían convertirse en una expropiación del gobierno a pesar de que una parte privada realice la expropiación real de los intereses: (1) cuando el gobierno exige la acción privada; (2) cuando hay suficiente nexo entre la aprobación del gobierno y la acción privada; y (3) cuando el gobierno autoriza la acción privada, y es previsible e inevitable que la expropiación ocurrirá como consecuencia.

\subsubsection{Cuando el gobierno exige la acción privada}

Está bien establecido que donde el gobierno exige que una de las partes se someta a la ocupación física de otra parte privada, hay una expropiación. En esta situación, el gobierno autoriza lo que se conoce como una expropiación física obligada ${ }^{126}$. Si el gobierno exige que una parte privada mineral tome control sobre la propiedad del dueño del mineral, o autoriza invasiones privadas sobre dichos bienes, podría ocurrir una expropiación. Típicamente, los gobiernos locales nunca exigen la invasión de superficie de la tierra por agrupaciones privadas. Si el gobierno ocupa físicamente tierra de propiedad privada con sus propios agentes o terceros, será considerado responsable por la expropiación ${ }^{127}$.

123. LAITOS. supra nota 119 , en 45.

124. Ver Mongrue v. Monsanto Co., 249 F.3d 422, 429-31 (5th Cir. 2001)

125. Ver Ridge Line, Inc. V. Estados Unidos de América, 346 F.3d 1346, 1355-56 (Fed. Cir. 2003).

La línea de distinción entre expropiaciones físicamente potenciales de los posibles agravios resulta de una investigación dividida en dos partes. Primero, la indemnización por pérdida de una propiedad como resultado de una expropiación tendrá lugar cuando el gobierno intente invadir una propiedad de interés protegido o la invasión señalada es la "directa, natural o probable resultado de una actividad autorizada y no por una lesión incidental o por consecuencia de la acción.".. [Segundo], una invasión debe reportarle un beneficio al gobierno a expensas del propietario, o por lo menos, se anticipa al propietario (sic) de su derecho de disfrutar su propiedad durante un período prolongado de tiempo, en lugar de limitarse a infligir una lesión que reduzca su valor. Id. (citando Columbia Basin Orchard v. Estados Unidos de América, 132 F. Supp. 707, 709 (1955)).

126. Ver Loretto v. Teleprompter Manhattan CATV Corp., 458 U.S. 419 (1982); Pumpelly v. Green Bay Co.; 80 U.S. 166 (1872).

127. Brown v. Estados Unidos de América, 73 F.3d 1100, 1103 (Fed Cir. 1996) (declarando que en dicha situación "la responsabilidad es una conclusión inevitable"). 
Incluso, cuando una entidad gubernamental por sí misma no se entrometió físicamente o expropió por completo la propiedad privada, el gobierno puede ser responsable por la expropiación si promulgó regulaciones que supusieron habilitar a las partes privadas a invadir o interferir con dicha propiedad ${ }^{128}$. Además, una expropiación se da cuando el gobierno permite a miembros del público a ingresar y usar la propiedad de otro ${ }^{129}$. En estos casos, es el hecho de que propietarios de minerales subyacentes no deseaban y no pudieron prevenir que la otra parte ingrese a la tierra lo que hace al gobierno responsable. Un propietario del subsuelo mineral puede argumentar que la autorización del gobierno para los proyectos de desarrollo de superficie para partes privadas es suficiente para considerar involucrado al gobierno y constituir una expropiación.

En contraste, cuando una parte privada voluntariamente permite la ocupación de otra parte privada, la Cláusula de Expropiaciones no aplica porque el gobierno únicamente regula las consecuencias de este permiso. Las regulaciones del gobierno para tratar lo que sucede después de los hechos no constituye suficiente acción del gobierno para activar la Cláusula de Expropiaciones. Por lo tanto, si el rol del gobierno es reducido a regular los efectos de la invitación, la Constitución no está implicada ${ }^{130}$.

\subsubsection{Cuando el gobierno tiene un nexo suficiente con la acción privada}

Cuando el gobierno aprueba una conducta por parte de una parte privada que puede dañar a otra, y el resultado es debido a la acción por parte del gobierno, probablemente habrá una expropiación. Esto es especialmente cierto cuando existe una relación cercana o nexo entre la parte privada que produce el daño y entre el gobierno ${ }^{131}$. Un contratista del gobierno que tiene permiso de este puede satisfacer este requerimiento ${ }^{132}$. Una entidad pública puede ser responsable por las acciones de la parte privada cuando esta tiene un compromiso con la misma para crear una "mejora pública"133. Sin embargo, lo más común es que los gobiernos sean responsables cuando ellos aprueban y aceptan la acción privada por razones de interés públi$\mathrm{Co}^{134}$. La aceptación a menudo toma forma de compromiso ${ }^{135}$. Más aún, la aceptación puede ser evidenciada por actos oficiales de dominio y control, tal como mostrar que la entidad pública hace trabajo de mantenimiento y reparaciones después del hecho ${ }^{136}$. Los propietarios del mineral rara vez enfrentan las aceptaciones gubernamentales de desarrollo de superficies hechas con partes privadas cuando esta se manifiesta junto con un compromiso o dedicación.

\subsubsection{El gobierno autoriza a la acción}

128. Loretto, 458 U.S. en 433, n.9 (1982). “Una ocupación permanente autorizada por una ley estatal es una expropiación sin tener en cuenta el estado o, en su lugar, sea una parte autorizada por el estado, la ocupante." Id.

129. Kaiser Aetna v. Estados Unidos de América , 444 U.S. 164 (1979); Nollan v. Cal Coastal Comm'n, 483 U.S. 825 (1987); Dollan v. Ciudad de Tigard, 512 U.S. 374 (1994).

130. Yee v. Ciudad de Escondido, 503 U.S. 519 (1992); FCC v. Fla. Power Corp., 480 U.S. 245 (1987).

131. Ver Bock v. Westminster Mall Co., 819 P.2d 55 (Colo. 1991).

132. Fowler Irrevocable Trust v. Ciudad de Boulder, 17 P.3d 797 (Colo. 2001); Ciudad de Northglenn v. Grynberg, 846 P.2d 175 (Colo. 1993).

133. Sheffet v. Condado de Los Ángeles, 3 Cal. App. 3d 720 (Cal. Ct. App. 1970).

134. Ullery v. Condado de Contra Costa, 202 Cal. App. 3d 562 (Cal. Ct. App. 1988); Blau v. Ciudad de los Ángeles, 32 Cal. App. 3d 77 (Cal. Ct. App. 1973)

135. Bargmann v. Nebraska, 600 N.W.2d 797 (Neb. 1999); Souza v. Silver Dev. Co., 164 Cal. App. $3 d 165$ (Cal. Ct. App. 1985); Steiger v. Ciudad de San Diego, 163 Cal. App. 2d 110 (Cal. Ct. App. 1958).

136. Yox v. Ciudad de Whittier, 182 Cal App. 3d 347 (Cal. Ct. App. 1986). 
privada, y el daño a otra parte privada es una consecuencia previsible e inevitable

Cuando la invasión física de la superficie de la propiedad dañada es una previsible e inevitable consecuencia de las acciones del gobierno local una compensación podría ser requerida. Las partes pueden recuperarse cuando la aprobación del gobierno sobre la acción privada necesariamente resulta en una expropiación de otra propiedad privada ${ }^{137}$. Esto es así porque un actor gubernamental "debe considerar las intenciones de las consecuencias naturales y ordinarias de sus acciones"138. Cuando los gobiernos locales dan permiso a las partes privadas para construir sobre propiedades mineras dañadas, ellos están, en efecto, revirtiendo el dominio ordinario del yacimiento minero. $\mathrm{Si}$ es una inevitable y natural consecuencia del permiso del gobierno que el propietario minero sea dañado y su yacimiento posiblemente sea expropiado por el dueño de la superficie sirviente, el gobierno tiene la responsabilidad constitucional con el yacimiento de los propietarios mineros por la interferencia de los propietarios de la superficie privada ${ }^{139}$.

Por otro lado, cuando el gobierno autoriza la acción privada pero esta no lleva inevitablemente a una expropiación, este no tiene responsabilidad por el resultante daño y el desarrollador no tiene recurso judicial. Cuando existe una autorización gubernamental de la acción privada, pero esta acción no lleva necesariamente a una invasión física de otro, no hay una aceptación por el gobierno. Como resultado, el gobierno no podrá ser demandado por las inintencionadas consecuencias de la acción privada. Los daños imprevisibles no son la consecuencia natural necesaria de la acción del gobierno ${ }^{140}$.

\section{2. ¿Ha habido una expropiación?}

Si la Cláusula de Expropiaciones aplica, la acción del gobierno en cuestión debe ser examinada para determinar si se ha dado una expropiación inconstitucional. Ciertos principios básicos de la jurisprudencia de expropiaciones pertenecen a los proyectistas contemplando una demanda de expropiación. El derecho de propiedad de un dueño de la tierra no es absoluto ${ }^{141}$. Dueños de la tierra y propietarios de minerales no son necesariamente conocidos por tener el uso más beneficioso de su propiedad. De hecho, el gobierno tiene amplia autoridad para interferir con las titularidades de los dueños de la tierra en nombre de la fuerza pública. Sin embargo, la Quinta Enmienda impone un límite del alcance dicha fuerza: una amplia interferencia regulatoria garantizará la compensación ${ }^{142}$.

De acuerdo a la Quinta Enmienda, generalmente una expropiación ocurre cuando el gobierno irrazonablemente interfiere con el derecho de propiedad de un dueño de la tierra. Dicha interferencia puede ser física o mediante una regulación. La ocupación física por el gobierno constituye per se una interferencia irrazonable

137. Trinity Broad. of Denver v. Ciudad de Westminster, 848 P.2d 916 (Colo. 1993); Tom Beuchler Constr. v. Ciudad de Williston, 413 N.W.2d 336 (N.D. 1987); Kite v. Ciudad de Westworth Village, 853 S.W.2d 200 (Tx. Ct. App. 1993).

138. Vokoun v. Ciudad de Lake Oswego, 56 P.3d 396, 401 (Or. 302) (citando Morrison v. Condado de Clackmanas, 18 P.2d 814 (Or. 1993)).

139. Del-Rio Drilling Programs, Inc. v. Estados Unidos de América, 46 Fed. Cl. 683 (2000).

140. Ver DiMartino v. Ciudad de Orinda, 80 Cal. App. 4th 329 (Cal. Ct. App. 329); Bargman, 600 N.W.2d en 797; Ullery v. Condado de Contra Costa, 202 Cal. App. 3d 562 (Cal. Ct. App. 1988).

141. Reeves v. Estados Unidos de América, 54 Fed. Cl. 652 (2002) (sosteniendo que cuando el proyectista reclamó su concesión minera en un área de estudio ambiental (Wilderness Study Area) (WSA, por sus siglas en inglés), el Bureau of Land Management adecuadamente denegó la solicitud del interesado para explorar y explotar debido a que el proyectista tenía una propiedad limitada por el WSA y las normas de no deterioro, bajo la Federal Land Policy y por la Management Act).

142. Pa. Coal Co. v. Mahon, 260 U.S. 393, 415 (1922) (declarando que la propiedad puede ser regulada, pero "si la regulación va muy lejos será reconocida como una expropiación".). 
garantizando una compensación ${ }^{143}$. Lo que constituye una irrazonable interferencia regulatoria requiere de un análisis más complejo. Existen dos casos en donde una regulación puede constituir una expropiación en ausencia de una ocupación física de la tierra. Primero, una expropiación regulatoria puede darse cuando la restricción sobre los intereses de la propiedad no persigue substancialmente el "legitimo interés del estado"144. Segundo, una expropiación regulatoria puede ocurrir cuando la aplicación de la restricción estatal o local "deniega el uso económico viable del dueño de la tierra sobre su tierra"145.

Usualmente, los intereses legítimos del estado se definen en general a favor del estado y gobiernos locales. Por ejemplo, una comunidad local puede constitucionalmente restringir el acceso a un yacimiento mineral prohibiendo su explotación si el hacerlo esta substancialmente relacionado con la salud, la seguridad y el bienestar general de la comunidad ${ }^{146}$. Además, si la minería causa o tiene un importante potencial para causar una alteración al orden público, puede ser prohibida sin importar si el desarrollador cumplió con todos los estatutos y regulaciones aplicables al caso ${ }^{147}$. En consecuencia, si una operación de un recurso en particular constituye una alteración al orden público, no se requerirá una compensación de acuerdo a la Quinta Enmienda. Además, cuando el gobierno caracteriza una acción restrictiva únicamente como un "retraso", temporal pero total, las prohibiciones en operaciones de extracción de recursos serán permitidas si persiguen algún interés público ${ }^{148}$.

Una regulación que promueve el legítimo interés del estado puede ser una expropiación sin compensación, incluso cuando le deniegue al dueño cualquier uso económico viable que le pudiera dar a la propiedad. Sin embargo, determinar el valor económico de la propiedad antes y después de la regulación es una tarea difícil ${ }^{149}$. Este análisis es incluso más difícil de hacer cuando existen yacimientos minerales involucrados, ya que definir la parcela relevante de la propiedad que ha sido "expropiada" (el denominador para determinar el valor económico) puede o no incluir el yacimiento mineral ${ }^{150}$. En algunos estados, por ejemplo, si la intención del dueño de la

143. Ver, e.g., Loretto v. Teleprompter Manhattan CATV Corp., 458 U.S. 419 (1982).

144. Lucas v. S.C. Coastal Council, 505 U.S. 1003, 1016 (1912).

145. Id. Pero, ver Kinross Copper Corp. v. Oregon, 981 P.2d 833, 835 (Or. Ct. App. 1999).

Los requerimientos del estado eliminaron a los solicitantes de concesiones mineras, dejándolas sin valor comercial dejando al solicitante sin derechos de propiedad por adquirir. Los solicitantes "no tienen el derecho de desarrollar su solicitud en violación de la ley estatal". Kinross, 981 P.2d en, p. 835.

146. Ver, e.g., Centre Line \& Stone Co. v. Spring Township Bd. Of Supervisors, 787 A.2d 1105 (Pa. Commw. Ct. 2001) (la interpretación de la ordenanza de zonificación excluyó totalmente la minería en la superficie y canteras del distrito forestal, y permitió la explotación de canteras en el 11\% del área total del municipio). Ver también, Goldblatt v. Hempstead, 369 U.S. 590 (1962) (no encontrando una expropiación a pesar de contar con una ordenanza que prohibía el dragado y la excavación de un pozo como un uso beneficio de la propiedad, dado que la extracción de minerales produce un daño a la comunidad y la ordenanza se aprobó como una medida de seguridad); Keystone Bituminous Coal v. DeBenedictis, 480 U.S. 470 (1987) (encontrando restricciones a la cantidad de carbón que puede ser extraído no era una expropiación donde el carbón en el subsuelo requería de ciertas estructuras para su apoyo en la superficie y su eliminación podía comprometer el bienestar general).

147. Machiopongo Land \& Coal Co. v. Dep't of Envtl. Prot., 799 A.2d 751, 754 (Pa. 2002)

148. Bass Enters Prod. Co. v. United States, No. 95-92 L., 2002 WL 31526504 (Fed. Cir. 2002). Mientras que perforar estaba prohibido bajo la Waste Isolation Pilot Plant Land Withdrawal Act a menos que la Agencia de Protección Ambiental denomine como necesaria la tierra para el cumplimiento con las disposiciones regulatorias finales o la Solid Waste Disposal Act, la demora por parte de la Agencia de Protección de Ambiental en denominar la tierra no constituyó una expropiación bajo Tahoe-Sierra Pres. Council Inc. v. Tahoe Reg. Plan. Agency, 535 U.S. en 302 (2002). Id.

149. Palazzolo v. R.I. 533 U.S. 606, 631(2001).

150. State ex rel. R.T.G., Inc. v. Ohio, 780 N.E.2d 998 (Ohio 2002) (“En determinar las parcelas relevantes para una expropiación regulatoria bajo el análisis de la Constitución del Estado, los derecho de carbón son divisibles y po- 
propiedad fuera de comprarla con el único fin de llevar a cabo minería del carbón subyacente, los derechos del carbón son divisibles y se consideran por separado respecto de los intereses de la propiedad ${ }^{151}$. En tal situación, solo se considera el valor del yacimiento mineral antes y después de la regulación en consideración.

Generalmente, sin embargo, el análisis apropiado toma en cuenta la parcela completa, incluyendo los derechos mineros ${ }^{152}$. En la determinación de las consecuencias económicas de un acto regulatorio, el tribunal debe considerar la parcela de tierra más afectada por la regulación, no solo la parte que contiene el recurso natural $^{153}$. Por lo tanto, en el caso de restricciones estatales y locales en el desarrollo de recursos, el paquete completo de titularidades es usualmente considerado como el denominador, no solo la parte donde las operaciones de los recursos se han visto afectadas. Debido a que las restricciones dejan parcelas, de la propiedad del dueño, intactas y no gravadas con el desarrollo del recurso, sigue existiendo viabilidad económica, por lo que no hay expropiación ${ }^{154}$.

Establecer un uso económicamente viable postregulación no es una tarea difícil de cumplir para el gobierno estatal o local. Si hay evidencia de una posible venta de recursos o de otros beneficios de la propiedad, no hay expropiación ${ }^{155}$. La jurisprudencia demuestra que si la tierra en cuestión mantiene algún valor económico, la regulación no constituirá una expropiación ${ }^{156}$. Es un caso raro cuando un desarrollador del recurso puede demostrar, en una investigación de hechos específicos, que una regulación estatal o local asciende a una expropiación ${ }^{157}$. Cuando la propiedad en cuestión retiene más del valor mínimo, pero el valor económico de la propiedad ha disminuido enormemente, la propiedad puede haber sido tomada por la regulación local si también ha derrotado las expectativas de inversión del dueño, y si el daño publico que se pretende mitigar con la regulación no es atribuible a la operación del dueño del recurso ${ }^{158}$.

drán ser considerados como si fuese una propiedad separada por si la intención dueño-propietario fue comprar únicamente la propiedad con el fin de explotar la mina de carbón."). Ver también, Machiopongo, 799 A.2d en 768-69 (citando Loveladies Harbor, Inc. v. United States, 28 F.3d 1171, 1181 (Fed. Cir. 1994) (La corte adopta una "aproximación flexible" para determinar como la propiedad está definida horizontalmente y en el caso reenviado tener en cuenta factores como la "unidad y contigüidad de la propiedad, las fechas de la adquisición, el paquete propuesto en el cual la parcela propuesta ha sido tratada como si fuese una sola unidad, la medida en que las explotaciones reguladas benefician a las explotaciones no reguladas, el momento de las transferencias, la inversión de los propietarios apoyados por las expectativas y los planes de los dueños de la tierra para el desarrollo ").

151. Machiopongo, 799A.2d en 751.

152. Animas Valley Sand \& Gravel, Inc. v. Bd. of County Comm'rs, 38 P.3d 59,68 (Colo.2001) (sosteniendo que a pesar de que Pensilvania se refiere al soporte accesorio como un interés separado de propiedad "el enfoque apropiado a una investigación de expropiación es tomar en cuenta los derecho de propiedad como un agregado, mas que simples derechos de explotación minera"); ver también Tahoe-Sierra, 535 U.S. 302.

153. Animas, 38 P.3d en 69. Per over, R.T.G., 780 N.E.2d. en 1009, (citando Loveladies, 28 F.3d en 1181) (donde se afirma que a pesar de propiedades contiguas son típicamente consideradas como una sola parcela de interés para fines de un análisis de expropiaciones, los matices de hecho podrían indicar un enfoque más flexible).

154. Animas, 38 P.3d en 69 (sosteniendo que el impacto económico sobre toda la parcela de tierra debería ser analizada, no únicamente los derecho sobre los minerales en donde la operación en arena y tierra estaba prohibida).

155. Ver Machipongo, 799 A.2d en 769-70 (concluyendo, dado que la regulación declaró a la propiedad como no apta para la minería no se le denegó al propietario todos los usos económicamente beneficiosos de la propiedad, como la capacidad para vender madera o entrar a los arrendamientos de petróleo y gas, no hubo una expropiación bajo el Lucas test).

156. Animas, 38 P.3d en 66 ("“-[E]I nivel de interferencia [con la propiedad del dueño de la tierra] debe ser bastante alto.")

157. Id. (citando Palazzolo v. R.I., 533 U.S. 606, 630 (2001)) (donde una investigación específica de hechos fue requerida en donde el valor de la tierra se redujo en un $93 \%)$.

158. Animas, 38 P.3d en 66 (donde se afirma que entre los factores que deben tenerse en cuenta son la naturaleza de la regulación, el impacto económico de la regulación y el impacto del plan en las expectativas de inversión respaldada). 
Desafortunadamente, incluso cuando un terrateniente pueda tener reclamos válidos respecto de la expropiación, el dueño del recurso debe superar un obstáculo constitucional crucial antes de que la propiedad pueda ser liberada de la regulación, de acuerdo a la Quinta Enmienda. Un reclamo con respecto a una expropiación debe estar maduro antes de poder ser considerado. Cuando hay remedios administrativos disponibles para el propietario del recurso, un reclamo frente a la expropiación no está suficientemente maduro como para ser revisado por un tribunal a menos que fuera "inútil" someterse a dichos ejercicios administrativos ${ }^{159}$. Además, si la entidad local encargada de implementar la regulación no ha alcanzado su decisión final con respecto al alcance de la resolución y la consecuente pérdida de valor de la propiedad del dueño de la tierra, un reclamo respeto de la expropiación no está suficientemente maduro para ser revisado ${ }^{160}$. Mientras que los derechos constitucionales teóricamente existen como una capa que reemplaza los poderes públicos locales, se ha probado que acceder a dicha herramienta es bastante difícil.

\section{BARRERAS REGULATORIAS SECUENCIALES ESTATALES Y LOCALES}

Entender y resolver las capas verticales de la regulación no es el fin de la difícil prueba para el proyectista. La relación tumultuosa entre el proyectista de extracción y el gobierno estatal y local, así como los conflictos entre el proyectista y las partes privadas, continúa horizontalmente a través del ciclo de vida del desarrollo del recurso. Los proyectistas están estrictamente regulados antes de tener el permiso y durante la producción, así como en las etapas post-producción. Los agentes estatales y locales inicialmente regulan y restringen operaciones existentes cuando el permiso para el desarrollo es buscado ${ }^{161}$. Las obligaciones regulatorias continúan a través de las fases de extracción y producción y permanecen, incluso, luego de terminadas las operaciones. Los gobiernos locales, citan el poder público como la autoridad para la zonificación y otras técnicas regulatorias tradicionales empleadas en la tierra no aprobada de otro modo por ley estatal ${ }^{162}$. Las herramientas que los gobiernos locales usan para regular la industria extractora durante el ciclo de vida de la operación incluye el uso condicional de permisos, usos no conformes, y moratorias. Usualmente, estas restricciones son impuestas inesperadamente, de tal manera que el desarrollador no puede anticiparlas o prepararse para ellas. Como resultado de esta regulación implacable y en constante cambio, los desarrolladores deben dedicar tiempo, recursos y talento legal a la tarea de buscar superar ronda tras ronda de obstáculos regulatorios.

\section{Obtener permiso para desarrollar}

Antes de poder presentar la solicitud para un permiso, el proyectista debe tener los derechos legales para desarrollar un recurso en particular. La interpretación de las cortes del lenguaje de la escritura puede llevarlos a denegar a un

159. Southdown, Inc. v. Jackson Township Zoning Hearing Bd., No. 1656 CD. 2001, 2002 WL 31414460 (Pa. Commw. Ct. 2002) (constatando que la negación de un negocio de una cantera de piedra caliza con un permiso especial y excepcional no estaba listo para su revisión pues la empresa no había solicitado, todavía un cambio de zonificación o la varianza).

160. Daddario v. Cape Cod Comm'n, 780 N.E.2d 124, 128 (Mass. App. Ct. 2002) (Encontrando que no es posible, sin mayor interacción entre el demandante y la Comisión, determinar la viabilidad económica de una operación minera en la arena o grava podría ser identificado y que sea aceptable para la Comisión).

161. Ver Fiske \& Lane, supra nota 4, en 15-2 (se explica que los gobiernos locales han promulgado regulaciones al petróleo y gas y permitiendo requerimientos que crean costos adicionales, demora, y espacio para más negativas regulatorias para los proyectistas).

162. WOZNIAK, supra nota 55, en 12-40. Los gobiernos locales se han vuelto mucho más sofisticados en el cumplimiento de sus facultades para uso de la tierra. En lugar de denegar permisos, citan el poder policía como un justificante para casi todas las condiciones que no está establecidas en el permiso estatal o en las regulaciones estatales. Id. 
proyectista el permiso para desarrollar un recurso $^{163}$. Distintos métodos de interpretar que recursos son transmitidos en dicho lenguaje puede llevar a una imprevisibilidad para los proyectistas de recursos naturales. Por ejemplo, las distintas jurisdicciones usan distintas reglas y razonamiento para determinar que parte, el arrendatario de gas o carbón, posee metano en yacimientos de carbón ${ }^{164}$. Las cortes estatales han luchado para articular una regla clara a seguir, y los "casos considerados en conjunto demuestran un razonamiento confuso e inconsistente" 165 . A menudo, las cortes estatales aplican leyes contractuales en un método de caso a caso para determinar la intención de las partes en una escritura de transporte particular. El conflicto de análisis entre tribunales dificulta al proyectista el poder anticipar una clara regla de interpretación.

Luego de que los asuntos de la propiedad se aclaran, los proyectistas hacen frente a dificultades al asegurar permisos para extraer y producir recursos ${ }^{166}$. Muchos condados pueden preferir prohibir operaciones mineras en su totalidad. Sin embargo, dicha prohibición absoluta de aprobar el permiso puede ser atacada basán- dose en que es "arbitraria y caprichosa y en desacuerdo con la ley del estado"167. En lugar de una prohibición absoluta, algunas municipalidades utilizan modernas técnicas de zonificación con la intención de adaptar la extracción de recursos a las necesidades particulares del lugar. Permisos de uso condicional, permisos de uso especial o permisos especiales de excepción dan a las localidades completa y final discreción sobre que uso extractivo puede ser permitido.

En algunos casos, el gobierno estatal o local puede negarle al desarrollador la oportunidad de obtener un permiso luego de haber iniciado el proceso regulatorio. Esta pérdida de la oportunidad de desarrollar ocurre mientras que el desarrollador está esperando la aprobación o denegación de la solicitud al permiso, pero luego de que el desarrollador ha gastado considerables fondos en el cumplimiento con procedimientos aplicables y evaluaciones medioambientales. El desarrollador confía en la asunción de que puede obtener una decisión de ir o no ir respecto de la solicitud ${ }^{168}$.

Si el permiso está garantizado, puede contener limitaciones en el desarrollo como resultado de

163. Newman v. RAG Wyo. Land Co., 53 P.3d 540 (Wyo. 2002) ((interpretando la escritura de transferencia "todo el carbón y minerales mezclados con carbón que puedan ser explotados o extraídos en asociación con los mismos o en conjunto con las operaciones de carbón tipo" y las reservas de "todo petróleo, gas y otros minerales" para reservar a los propietarios todo el metano en capas de carbón) Ver también, Kickman v. Groves, 71 P.3d 256 (Wyo. 2003) (encontrando que una escritura de 1944 contenía el término "derechos petroleros" no está claro si esta frase incluía al petróleo y gas, incluida o excluía al GMC, o si incluía únicamente derecho petroleros sin ningún tipo de derechos gasíferos).

164. Newman, 53 P.3d en 546-48 (concluyendo que las diferentes reglas utilizadas para determinar la propiedad del GMC, tales como la teoría de la "propiedad del lugar" y la "regla de la captura", regla utilizada en jurisdicciones de Pensilvania, Alabama y Montana, hacen una regla clara difícil de articular). Ver supra Parte II.A.2 (explicando las dificultades que los proyectistas enfrentan en determinar si los derechos GMC pertenecen al gas o al carbón).

165. Newman, 53 P.3d en 548.

166. Ver e.g., Eugene Sand \& Gravel v. Lane County, 74 P.3d 1085 (Or. App. 2003) (devolver el caso a la Junta de Usos de Suelo para que determine si la solicitud de permiso presentada por la compañía minera cumplía con los requerimientos para minimizar los conflictos entre la minería y la agricultura, donde la operación de retail en un stand granjero fue considerada una "práctica de agricultura").

167. Wozniak, supra nota 55, en 12-40.

168. Ver, e.g., Hermosa Beach Stop Oil Coalition v. City Of Hermosa, 86 Cal. App. 534 (Cal. Ct. App. 2001) (encontrando que en donde los votantes de la ciudad aprueban una iniciativa de restablecer la prohibición total de extracción de petróleo en la ciudad, debido al poder policía de la ciudad, no violó las cláusulas contractuales de la Constitución de los Estados Unidos por aplicar una ley a una compañía petrolera incluso si después, la empresa firmó un contrato de arrendamiento con la ciudad para la exploración y producción de minerales); Seven-Up Joint Venture v. Mont., Cause No. BDV-2000-250 (Mont. Dist. Ct. Dic. 10 de 2002) (concluyendo que no fue un impedimento 
condiciones adjuntas a los permisos ${ }^{169}$. En teoría, el permiso de un solicitante para la minería puede tener tantas condiciones que se convierte en poco práctico o hace imposible el desarrollo de la propiedad subyacente. Aún si no se mantiene un uso económicamente viable, se presenta una expropiación ${ }^{170}$. Si el desarrollador busca un permiso de uso en especial, esta solicitud será revisada por la localidad en base al método de caso a caso para determinar si el solicitante ha presentado evidencia substancial de que su propósito de uso cumple con los requerimientos legales. Por supuesto, las comisiones de zonificación y planeamiento pueden negar un permiso aplicando incorrectamente los reglamentos de zonificación $^{171}$. Las juntas de zonificación local que deniegan una aplicación por una revisión especial pueden ver revocada su decisión si la misma no fue hecha de conformidad con los términos de la ley en cuestión ${ }^{172}$.

Cuando se les otorga a los desarrolladores permisos de uso condicional, ellos pueden requerir que el desarrollador gaste enormes sumas de dinero antes de iniciar el proyecto en respuesta a intereses locales con respecto al medio ambiente, la cultura, o estética. Las municipalidades pueden ordenar la aprobación de un permiso especial para considerar el efecto que una operación minera tendrá en los recursos culturales de un área particular antes de aprobar el desarrollo ${ }^{173}$. Los planes integrales pueden requerir de comisiones de zonificación y planeamiento para evaluar los efectos adversos del desarrollo de recursos sobre activos visuales, como recursos arqueológicos e históricos, en contra de la ventaja económica obtenida a nivel local por una propuesta de uso condicional ${ }^{174}$. Un desarrollador, también tendrá que estudiar y considerar los efectos en las propiedades contiguas ${ }^{175}$. Las preocupaciones locales son de primordial interés de tal manera que algunas leyes estatales permiten a la junta local de zonificación a ser más flexibles con los desarrolladores que están dispuestos a incorporar explícitamente los intereses locales a su proceso de desarrollo ${ }^{176}$.

inconstitucional del contrato, donde el estado de por terminado un acuerdo de arrendamiento minero entre sí mismo y un proyectista, mientras este se encuentre esperando la aprobación o denegatoria del permiso).

169. Wozniak, supra nota 55, en 12-40. ("Mientras los gobiernos locales continúen el condicionamiento del proceso los límites entre la regulación local y estatal seguirá evolucionando en cada jurisdicción.") Ver, Native Vill. Of Eklutna v. Bd. Of Ajustment, 995 P.2d 641, 646 (Alaska 2000) (citando AMC 21.50.070 (C)) (La Comisión debe adjuntar tantas condiciones encuentre necesarias para la extracción de un recurso natural de uso condicionado."). Ver también, Protect Our Waters v. County of Merced, 110 Cal. App. 4th 362 (2003) (revertir la aprobación del Condado de un proyecto para extraer 15 millones de toneladas de reserva agregada en $\mathbf{4 5 6}$ hectáreas debido a que los archivos administrativos estaban tan pobremente organizados que la corte no pudo determinar si el condado había cumplido con la ley).

170. Ver supra Parte II.C.

171. Merlin Meyers Revocable Trust v. Yellowstone County, 53 P.2d 1268 (Mont. 2002) (constatando que el condado se equivocó en su decisión de denegar la solicitud de revisión especial para extraer grava en un mira a tajo abierto en un área no residencial pues el área no estaba sujeta a la regulación local de zonificación que se aplican en áreas residenciales).

172. Id. en 1272. La Corte Suprema de Montana sostuvo los comisionados del condado no pueden denegar la solicitud para revisión especial porque consideran que la ley puede ser inconstitucional. Como un brazo del Poder Ejecutivo, los comisionados del condado deben aplicar la ley mientras que declarar la inconstitucionalidad de una ley le pertenece al Poder Legislativo. Id.

173. Eklutna, 995 P.2d en 641 (reenviando un permiso de uso condicional (PUC) para una operación minera de granito, debido a que la comisión de planificación no consideró los efectos de la concesión de un PUC entre colinas gemelas podría tener un significado cultural como fue denominado posteriormente el pueblo nativo).

174. Id.

175. Evans v. Bd. Of Comm'rs, 50 P.3d 443 (Idaho 2002) (encontrando que permiso de uso especial con treinta y dos condiciones adjuntadas que contenía suficiente información previendo los efectos en propiedades colindantes para satisfacer los requisitos legales porque no había evidencia sustancial presentada en la audiencia).

176. Nicolet Minerals Co. v. Town of Nashville, 641 N.W.2d 497 (Wisc. C.t App. 2002) (constatando de que la ley en cues- 
Los condados se están volviendo audaces en la implementación de sus poderes de zonificación antes de que el desarrollo del recurso empiece ${ }^{177}$. Los reglamentos de zonificación provisionales y moratorias son implementados por municipios, efectivamente prohibiendo toda nueva operación por un plazo fijo ${ }^{178}$. Estas técnicas están justificadas como procedimientos de "emergencia", y ponen fin a todos los demás permisos mientras la localidad estudia si la reglamentación integral podría ser necesaria ${ }^{179}$.

\section{Durante el desarrollo del Recurso}

Una vez que el desarrollador obtiene el permiso, una interferencia con sus operaciones puede ocurrir por medio de diversas fuentes ${ }^{180}$. El rol del estado puede disminuir, mientras la jurisdic ción local puede ejercer incluso más poder ${ }^{181}$. Con estos cambios, el desarrollador puede estar operando bajo riendas apretadas. Lo más probable es que la autoridad local que dio el permiso no se desviará de la autorización ${ }^{182}$.

La interferencia con operaciones mineras, también puede provenir de fuentes no gubernamentales. Disputas contractuales pueden surgir entre los desarrolladores y los dueños de las propiedades minerales, incluso cuando la tierra del dueño de la propiedad se encuentra a varias millas de la explotación de minerales ${ }^{183}$. Además, los conflictos pueden surgir cuando los proyectistas del mineral cruzan la propiedad del dueño de la tierra para llegar a sus concesiones mineras $^{184}$. La rezonificación puede dar lugar a conflictos entre los propietarios de la superfi-

tión, sin ambigüedades, creó una excepción a las leyes de zonificación general y permitió a los gobiernos locales combinar el uso del suelo permisos con autorizaciones en un solo acuerdo, a cambio de pagos y la atención a las preocupaciones locales acerca de la minería. La corte argumentó que no había incentivos para que la empresa minera negocie un convenio conforme a la ley si no se permitiría a los gobiernos locales eludir los procedimientos ordinarios de zonificación.).

177. Ver e.g., Beaver Sand \& Gravel, Inc. v. Douglas County, 65 P.3d 1123 (Or. Ct. App. 2003) (acordando con el condado que una ley estatal no permite la emisión de permisos mineros para sitios de agregados no significativos). NOLON, supra nota 85, en 73 (notando que leyes locales recientes se están volviendo mucho más agresivas en sus ambiciones ambientales. La ley responsable de los problemas de calidad del agua y de la destrucción del espacio abierto de la nación es la ley local ambiental adoptada por la legislatura de la ciudad, pueblo y villa).

178. Mont. Code. Ann. § 76-2-206 (2001). En Montana, los Distritos con zonificación provisional están autorizados en situaciones de emergencia por el período de un año y con la posibilidad de renovarse. El 2 de julio de 2002, Gallatin County adoptó una moratoria en todos los permisos de GMC. El 13 de mayo de 2002, Delta County, Colorado adoptó una moratoria temporal (9 meses) en los permisos del GMC.

179. WOZNIAK. Supra note 55, en 12-36.

180. Ver e.g., Preserve the Dunes v. Dept. of Envtl. Quality, 655 N.W.2d 263 (Mich. Ct. App. 2002) (encontrando que un operador de una mina de arena cuya operación por dos años no calificó para una modificación en su permiso para expandir sus operaciones hacia una zonas críticas de dunas de arena pues las excepciones porque las excepciones la prohibición legal en dichas áreas estaba limitada a operadores y no operaciones que existían antes de 1989).

181. Peeples Inc. V. State Land Dep't, 59 P.3d 831, 834 (Ariz. 2002) (El departamento estatal de suelos no pudo reevaluar la características minerales de los contratos de arrendamiento por razones económicas después de la celebración del contrato de arrendamiento para la explotación de minerales, ya que sólo hay una autoridad legal para hacerlo antes de que el contrato de arrendamiento se celebre.).

182. Swift v. Sublette County Bd. of County Comm'rs, 40 P.3d 1235 (Wyo. 2002). Las solicitudes para permisos de uso condicional a incluir una planta dosificadora de hormigón en un sitio de cantera de grava fue denegada porque la planta de procesamiento no es una "extracción asociada" con la operación de cantera de grava. Los permisos se limitan, estrictamente, a los términos del permiso, tal como se define en las regulaciones de zonificación. Id.

183. McNeill v. Rice Eng'g \& Operating, Inc., 70 P.3d 794, 800 (N.M. Ct. App. 2003) (encontrando que un "Comunicado de Daños a la Propiedad" era ambiguo y claramente no era un contrato de cesión de agua salada en donde la compañía minera, de conformidad con el acuerdo, dispondría del agua salada para las operaciones de petróleo y gas tanto dentro como fuera del propietario del suelo sin la autorización del mismo).

184. Weisiger v. Harbour, 62 P.3d 1069 (Colo. Ct. App. 2002) (encontrando que un empresario minero tuvo una prescrip- 
cie y por otro lado de los minerales ${ }^{185}$. Adicionalmente, los locales algunas veces toman el asunto por sus propias manos bloqueando las carreteras de acceso a los yacimientos mineros en protesta por los efectos secundarios de las operaciones de extracción de recursos ${ }^{186}$. Aunque, estas técnicas no son legalmente defendibles, son impedimentos prácticos a la operación del desarrollador del recurso.

Una vez que las operaciones se están realizando, las comisiones de zonificación pueden restringir una industria extractora mediante la rezonificación del área. En estas áreas re zonificadas, no serán permitidas nuevas operaciones de extracción de recursos. Sin embargo, las operaciones existentes pueden constituir usos no conformes (UNCs). Un uso particular del suelo alcanza el estado de un UNC cuando el uso es "establecido" antes de que la ordenanza de zonificación sea instaurada. Incluso, las operaciones de recursos existentes designadas como UNC están sujetas a limitaciones locales. Por ejemplo, los usos no conformes, generalmente no pueden ser cambiados o expandidos en tamaño. Una excepción a esta regla aplica a la extracción de un bien no renovable, debido a que la extracción de dichos bienes como son los recursos minerales requieren de la expansión de un área de la tierra. Para que aplique la excepción de este tipo de bienes, los desarrolladores deben exteriorizar la "manifestación de su interés" por usar todo lo determinado en una parcela en particular al momento de establecer el uso no conforme. Se ha demostrado que este es un estándar difícil de satisfacer ${ }^{187}$.

Incluso, cuando un desarrollador muestra manifiestamente su interés, prevalecerá el derecho reconocido de los municipios para limitar usos anteriores no conformes y para volverlos conformes con posteriores ordenanzas de zonificación promulgadas $^{188}$.

Si un municipio zonifica la tierra luego de que un desarrollador haya obtenido un permiso, pero antes de que establezca las operaciones mineras, no existirá un uso no conforme ${ }^{189}$. Un derecho adquirido puede ser establecido, sin embargo, cuando un operador del recurso incurre en costos substanciales y si las actividades físicas realizadas a manera de pre-operación constituyen "minería" de acuerdo a la ley pertinente ${ }^{190}$. Un derecho adquirido, inmuniza a su titular de la regulación impuesta posteriormente.

ción de servidumbre sobre la propiedad del dueño del suelo, donde el empresario empezó a cruzar la propiedad del dueño del suelo porque una nueva subdivisión obstruía su acceso al camino de la mina. La "mínima desviación" no afectó el período de prescripción de 18 años.).

185. Saddle Mountain Mineral v. Joshi, 65 P.3d 366 (Wash. Ct. App. 2003) (encontrando de que no existía nada en el código que señalara expresa o implícitamente que la rezonificación causó que el dueño de los minerales pierda sus títulos legales de sus derecho mineros, se mantuvo una cuestión de prisión preventiva si el propietario de la superficie tomó ilegalmente arena y grava de la finca mineral).

186. Ver, e.g., Wyo. Res. Corp. v. T-Chair Land Co., 49 P.3d 999 (Wyo. 2002) (constatación de que la empresa minera no tenía derecho a impedir que los miembros del sindicato protesten desde una carretera de acceso a la zona minera debido a que se encontró que existe una vía pública histórica); Fed-up Ranchers Lock Out Drillers, Denver Post, 26 de noviembre de 2002, en $1^{\text {a }}$ (los rancheros pusieron candados en sus puertas para mantener alejadas a las compañías de energía).

187. McDowell, Inc. v. Bd. of Adjustment, 757 A.2d 822 (N.J. 2000) (conclusión de que el mero hecho de que la naturaleza del uso implica una disminución de activos no necesariamente justifica su expansión, el dueño debe demostrar que la zona entera fue "dedicada" a la actividad minera).

188. Ver Id. en 834.

189. Pero ver, Bd. of Adjustment v. Wende, 92 S.W.3d 424, 432 (Tex. 2002) (la conclusión de que el dueño de la cantera estableció un uso no conforme, en donde el código define el "uso" como el propósito para el cual la tierra se arrien$\mathrm{da}$, y donde el operador de cantera ha arrendado parcelas de una tierra adyacente a una cantera existente para la explotación de canteras antes de su anexión y zonificación).

190. Vulcan Materials Co. v. Greenville County Bd. of Zoning Appeals, 536 S.E. 2d.892, 901 (S.C. Ct. App. 2000) (la búsqueda de un derecho válido creado para obtener un permiso para la operación de explotación de canteras en las que los proyectistas gastan casi dos millones de dólares y cuyas actividades física en la tierra constituía la minería). 


\section{Luego de cesar la Producción}

Incluso, luego de que la operación de extracción de un recurso ha sido completada, la relación del desarrollador con los reguladores del gobierno estatal y local continúa. Un operador de petróleo y gas puede estar obligado a tapar un pozo incapaz de producir petróleo o gas en cantidades comerciales. Algunas veces no queda claro quién, entre varios dueños, está obligado a asegurar que el bien está tapado, bajo la ley estatal ${ }^{191}$.

Además, los proyectistas comprometidos con operaciones mineras sobre superficies de carbón se enfrentan a detallados requisitos de recuperación post-minería. La Ley Federal de Recuperación de la Superficie de Minas de Carbón (LFRSMC) fue promulgada con la finalidad principal de establecer un "programa a nivel nacional para proteger... el medio ambiente frente a los efectos adversos de la superficie en las operaciones sobre minas de carbón"192. La LFRSMC establece requisitos federales mínimos de recuperación, y los estados pueden añadir disposiciones más rigurosas ${ }^{193}$. De acuerdo con la LFRSMC, las leyes estatales requieren que "las operaciones en las minas reciban permisos, que archiven bonos a pagar por las recuperaciones no ejecutadas, y que cumplan con los estándares de desempeño ambiental"194. Las compañías mineras deben obtener permisos de minería de superficie de conformidad con la LFRSMC ${ }^{195}$. Además, deben pagar bonos luego de que la minería haya sido completada para cubrir el daño que se haya producido durante sus operaciones. Los litigios pueden surgir en torno a la determinación de una comisión de recuperación que los bonos deben ser perdidos cuando una empresa no se comprometa adecuadamente con la recuperación ${ }^{196}$.

Finalmente, décadas después de que la minería haya terminado, los proyectistas mineros pueden ser responsables de limpiar los desperdicios que fueron producidos y desechados durante la operación. La Ley de Respuesta, Compensación y Responsabilidad Integral Ambiental (LRCRIA) es una ley retroactiva de respuesta federal diseñada para limpiar vertedores de residuos inactivos que resulten peligrosos ${ }^{197}$. La responsabilidad bajo la LRCRIA es provocada cuando hay una "fuga" de algún "vertedor" de "sustancias peligrosas" en cualquier "centro". Los desechos mineros son considerados"sustancias peligrosas" bajo la LRCRIA ${ }^{198}$. Muchas veces, la responsabilidad ocurre porque los centros mineros tienen túneles de drenaje o desechos de operaciones mineras inactivas ${ }^{199}$. Los metales

191. Ver B \& D Drilling v. Ohio, No. O2AP-52, 2002 WL 31111853, en *1 (Ohio App. 10 Dis. 24 de septiembre de 2002) La corte encontró que el dueño es la parte obligada a tapar un pozo de petróleo incapaz de producir petróleo o gas en cantidades comerciales. El pozo deberá ser tapado una vez que el Jefe de la División de la Oficina de Gestión de los Recursos Minerales haga tal afirmación y no, cuando el propietario afirme que el pozo es improductivo. Id.

192. 30 U.S.C. §1202(a) (1994).

193. Id. $\S 1255(\mathrm{~b})$.

194. RUBENSTEIN , A. Brooke y WINKOWSKI, David. A Mine is a Terrible Thing to Waste: Past, Present, and Future Reclamation Efforts to Correct the Environmentally Damaging Effects of Coal Mines. 13 Vill. Envtl. L.J. 189, 200 (2002) (citando 30 U.S.C. §§ 1256-64).

195. Ver también, DK Excavating, Inc. v. Miano, 549 S.E.2d. 280 (W. Va. 2001) (La actividad del dueño del suelo que no constituya "minería de superficie" bajo la ley local, aún así deberá solicitar un permiso de la SMCRA).

196. Ver, Ex parte Van Am. Ins. Co., 843 So.2d 180, 185 (Ala. 2002) (donde se afirma que, donde una empresa no reclame por la propiedad que era responsable de la recuperación, la corte no puede ordenarle a la empresa a pagar los bonos, porque el Alabama Surface Mining Commission Administrative Code Rules permite a la Comisión a dar a las empresas la opción de presentar un plan de recuperación o pagar los bonos).

197. LAITOS. Supranota 118, en 105.

198. 42 U.S.C. $\S 9607($ a) (2004).

199. Idaho v. Hanna Mining Co., 699 F. Supp. 827, 833 (D. Idaho 1987), aff'd, 822 F.2d 392 (Noveno Cir. 1989) (encontrando que los desechos mineros provenientes del procesamiento del cobalto y del cobre eran sustancias peligrosas). 
pesados tóxicos se escapan de los centros y contaminan la superficie de los suministros de agua ${ }^{200}$. Las partes potencialmente responsables incluyen a los operadores mineros que ya no están involucrados desde que abandonaron la mina ${ }^{201}$. Ellos enfrentan una responsabilidad retroactiva estricta y solidaria por los costos de la limpieza.

El típico desarrollador de recursos minerales es micro-gestionado horizontalmente, a través del ciclo de vida de la operación del recurso. Esta regulación es cada vez más local, creando nuevos y más rigurosos requerimientos para el desarrollador. Se necesita un marco de trabajo para informar a los proyectistas de lo que les depara el futuro antes de iniciar el proceso de obtención del permiso. Igualmente, las localidades se beneficiarían de un sistema por adelantado, con una sola parada antes de dar el permiso para así evitar repetidos y costosos obstáculos en las regulaciones a los proyectistas.

\section{CONCLUSIÓN}

Por su propia naturaleza, la regulación estatal y local sobre recursos no es uniforme. Lo que está permitido en un condado puede estar prohibido en el siguiente. Un estado puede tener una política de incentivar la extracción de recursos mientras que el estado vecino puede desplegar severas limitaciones medioambientales. Este hecho por separado hace que la presencia de leyes estatales y locales se convierta en una difícil y confusa barrera inherente a los proyectistas de recursos naturales que buscan extraer recursos en tierras no-federales.

Lo que ha agravado esta normal y comprensible realidad geográfica es una serie de leyes, reglas y restricciones estatales y locales que producen prácticamente efectos punitivos. Estas regulaciones no-federales impactan adversamente a los aspirantes proyectistas de dos maneras: (1) crean un número de conflictos de "elección de ley" que deben ser resueltos; $y$ (2) se presentan en serie, y usualmente de manera inesperada, a través del ciclo de vida de la operación. Con el desarrollo del carbón metano, se presenta una capa adicional de incertidumbre por una confusión estatal y local de preguntas jurisdiccionales. Hoy en día, ningún proyecto de extracción de un recurso puede ser completado exitosamente hasta que estos problemas hayan sido negociados y litigados de manera definitiva.

El tiempo y esfuerzo que los proyectistas y los gobiernos estatales y locales gastan peleando por asuntos legales que inevitablemente se presentan con múltiples capas y barreras secuenciales para el desarrollo del recurso parecen ser innecesarios y prácticamente un desperdicio. Los proyectistas minerales y el mercado de desarrollo de recursos americano necesitan una alternativa más eficiente ante los actuales asuntos del estado. Nuestra sugerencia es que cada estado adopte un estatuto integral de recursos naturales que (1) resuelva las ambigüedades estatales y locales sobre la autoridad regulatoria, (2) establezca los derechos relativos y deberes de los dueños de los propietarios de bienes divididos, y (3) permita únicamente la regulación local concordante con la Quinta Enmienda de la Constitución. Dicho estatuto deberá a su vez permitir a las localidades imponer, por adelantado en el proceso de permisos, una serie casi completa de los requisitos ambientales y de uso de la tierra que deberán ser seguidos por el desarrollador antes, durante y después de que el proyecto sea completado.

Si los estados adoptaran dichos estatutos, una gran parte de la confusión regulatoria estatal y local, sobre regulaciones de recursos naturales, estaría resuelta. Los proyectistas podrían dedicar su atención a cumplir las leyes com-

\section{LAITOS. Supra nota 118, en 116.}

201. Ver Coeur D’Alene Tribe v. Asarco, 280 F. Supp. 2d 1094, 1112 (D. Idaho 2003), (citando 42 U.S.C. §6903(3)) (encontrando que la migración de agua pasiva contaminante de los relaves en el río Couer D’Alene y en el Lago Coueur D'Alene, sin ayuda de conducta humana, constituía una "liberación" a los efectos del CERCLA a pesar de que la liberación de las sustancias ocurrió décadas antes de la promulgación de la ley). 
prensibles en vez de estar discutiendo con gobiernos locales acerca de la mejor manera de interpretar una confusa orientación legal. Los recursos podrían ser extraídos consistentemente con los estándares estatales y locales. Los proyectistas podrían asegurar fácilmente que se cumplan las necesidades ambientales, de seguridad y sociales, en vez de tener que contratar batallones de abogados para pelear con los gobiernos locales en cada etapa del desarrollo. Los gobiernos locales podrían dedicar más tiempo a la planificación y supervisión de estas operaciones y menos tiempo a aspectos de la corte. La realidad jurídica actual está muy lejos de esta situación. Si la eficiencia se restaurase, tanto el proyectista del recurso como el regulador estatal-local estarían mejor servidos. 